\title{
The effectiveness of personalised versus generic information in changing behaviour: Evidence from an indoor air quality experiment*
}

\author{
Rita Abdel Sater ${ }^{\dagger \ddagger} \quad$ Mathieu Perona ${ }^{\S} \quad$ Elise Huillery $\mathbb{I}^{\mathbb{I}} \quad$ Coralie $^{\text {Chevallier }}{ }^{\dagger}$
}

August 2021

\begin{abstract}
While indoor air pollution is one of the leading causes of morbidity and mortality worldwide, its sources and impacts are largely misunderstood by the public. In a randomized controlled trial including 281 households in France, we test two interventions aimed at raising households' awareness of indoor pollutants and ultimately improving indoor air quality. While both generic and personalised information increase awareness, only personalised information is successful in shifting behaviour and decreasing indoor air pollution - by $20 \%$ compared to the control group. Heterogeneous treatment effects show that this effect is concentrated on the most polluted households at baseline.
\end{abstract}

*First and foremost, we are deeply indebted to the Direction Interministérielle de la Transformation Publique (DITP) and the Direction Régionale et Interdépartementale de l'Environnement et de l'Energie (DRIEE), who made the evaluation possible and put in endless effort and collaboration with the research team, especially Mariam Chammat, Baptiste Lorenzi and Laurianne Vagharchakian. We thank the Ville de Paris for their collaboration, in particular Olivier Chrétien and Deborah Lemener. We are grateful to Aurore Grandin,Jeanne Bollée, Laudine Carbuccia, Ariane Grandin, Juliette Bénon, Irène Metz and Naël Kaddour for outstanding assistance to operations and research. Finally, and most importantly, we gratefully acknowledge the households who agreed to be part of this experiment for the time and information they shared with us. This research is supported by grant ANR-17-EURE-0017. The project was approved by the Institutional Review Boards at the Paris School of Economics (Reference 2019-016). This study is registered in the AEA RCT Registry and the unique identifying number is AEARCTR-0007980.

${ }^{\dagger} \mathrm{LNC}^{2}$, Département d'études cognitives, Ecole normale supérieure, Université PSL, INSERM, 75005 Paris, France

$¥$ Department of Economics, Sciences Po, Paris, France

$\S$ CEPREMAP, Paris, France

ILEDa, Université Paris-Dauphine, Université PSL, IRD, CNRS, 75016 Paris, France 


\section{Introduction}

Exposure to indoor and outdoor pollution is one of the leading causes of morbidity and mortality worldwide (Burnett et al. 2018; Landrigan et al. 2018; Lelieveld et al. 2020). Despite improvements in air quality over the past 10 years, $90 \%$ of European countries still record levels of PM2.5 (particulate matter with an aerodynamic diameter smaller or equal to $2.5 \mu \mathrm{m}$ ) above the safety threshold set by the World Health Organisation (EEA Air quality report, 2020). It is currently estimated that an annual loss of 2 million healthy life years can be attributed to indoor air pollution alone (Asikainen et al. 2016).

Given that residents in high-income countries spend more than $80 \%$ of their time in closed environments, exposure to air pollutants is largely determined by indoor air quality (N. Klepeis, Nelson, et al. 2001; Oar et al. 2014). Air quality inside is roughly the same as that recorded outside when there is no polluting indoor activity. However, when household polluting sources are activated, indoor air quality can be up to 5 times worse than outdoor air quality (Ebner et al. 2005). Household behaviour therefore significantly impacts the quality of indoor air. The main indoor sources of PM2.5 are combustion activities, with the largest emissions resulting from cooking, tobacco smoking and wood burning (Wallace et al. 2002; Long et al. 2000; Nasir et al. 2013; Frasca et al. 2018).

Residential wood burning, in particular, releases far more abundant and harmful volumes of pollutants than other activities such as car exhausts or cigarettes (Gras et al. 2002; Pryor 1992; Chafe et al. 2015; Hoek et al. 2008; Molnar et al. 2005), even when using certified, high-efficiency equipment (Frasca et al. 2018). Beyond sanitary risks for individual users, residential wood burning is also a major source of outdoor pollution, which means that private heating choices have collective consequences. While it provides only $3 \%$ of energy needs, residential wood burning is responsible for more than $45 \%$ of PM2.5 concentration in Europe, which makes it the leading source of outdoor air pollution, above transportation and the industry (Amann et al. 2018).

Yet, the general public is mostly unaware of the negative consequences of wood burning and other combustion activities. Wood, candles or incense burning is typically associated with positive feelings and considered natural, healthy and lowpolluting. This strong positive association distorts the perception of health and environmental risks, and is an obstacle to household behaviour change (Hine, Marks, et al. 2007). Bhullar et al. (2014) find that higher perception of wood smoke risk is indeed associated with higher support for wood burning regulation in Australia and a higher likelihood of switching to alternative heating. More generally, despite an increased awareness of air pollution, the public still has a limited apprehension of the 
factors that influence indoor air quality and its effects on health (Boso et al. 2018; Daniel et al. 2020; Grange et al. 2012; Hofflinger et al. 2019). Therefore, finding levers to increase awareness of the risks associated with wood burning and other household polluting activities is of key environmental and public health concern.

This paper tests the effectiveness of two interventions aimed at raising households' awareness of the risks associated with wood burning and other indoor pollutants, and in turn changing their behaviour to ultimately decrease air pollution. Using a randomized controlled trial in France, we equipped 281 households with air quality micro-monitors and assigned them to three conditions: the Information treatment, the Information + Personalised Emission Profile treatment, and the control group. The Information treatment consisted of weekly leaflets containing generic health-framed information on the risks related to indoor air pollution and multiple combustion activities, with special attention to wood burning. This treatment is expected to change households' behaviour by highlighting the health risks associated with combustion activities. The information was provided on a weekly basis during ten weeks to ensure proper assimilation and salience (Loewenstein 1996). The information was formatted in a way that facilitates a simple understanding of indoor polluting sources and its management (Van Raaij et al. 1983). An example of the Information treatment is shown in Figure A1 of the appendix.

Households in the Information + Personalised Emission Profile treatment were sent the same generic information along with a weekly Personalised Emission Profile of their indoor pollution levels, consisting of the graph of precise meter readings of the concentration of PM2.5 measured every five minutes over the previous week, as well as statistics to compare their emissions to similar households (the control group). An example of the Personalised Emission Profile is shown in Figure A2 of the appendix. Receiving real-time feedback in the form of a weekly Personalised Emission Profile is expected to reinforce the effect of generic information by activating complementary behavioural levers: first, it makes the hazards of wood burning more visible and allows people to think about which household activities are associated with subsequent PM2.5 peaks. Given that feedback is sent weekly, it is easy for households to remember what they did the previous week, which reduces imperfect information recollection. Second, building on prior research showing that social norms are an efficient lever of behavioural change (Allcott 2011; Goldstein et al. 2008; Ferraro and Price 2013; Stok et al. 2016), the Personalised Emission Profile activates social comparisons by providing participants with their rank compared to other households included in the study. Social comparison addresses biased beliefs about one's own consumption behaviour in comparison to others. For example, a person might underestimate her actual pollutant emissions when compared to other households. This biased belief can be corrected by a social 
comparison. Accordingly, social norms can constitute a reference point from which people do not want to deviate for fear of social disapproval. Social comparisons may also evoke feelings of competition.

Both treatments were implemented during ten weeks from January the 6th to March the 9th, 2020. To evaluate the impact of these treatments, we use highfrequency data on households' PM2.5 emissions over almost four months (four weeks before the interventions, ten weeks during the interventions, and two weeks after the interventions). The fixed cost of both the conception of the weekly interventions was estimated at EUR 30 per person. The cost of the Information treatment consists only in printing and mailing the leaflets, which amounts to approximately EUR 15 per person. The cost of the Information + Personalised Emission Profile leaflets is estimated at EUR 222 per person; this includes printing and mailing the leaflets (as the other treatment), plus renting the monitors, distributing and retrieving them, managing and replacing the defective ones and creating the personalised weekly leaflets.

We find that the Information + Personalised Emission Profile treatment was successful at decreasing indoor levels of PM2.5 by more than $20 \%$ over the fourmonth period, with a sustained and significant decrease starting on the 3rd week after the beginning of the intervention. Heterogeneous impact analysis reveals that the effect is concentrated on the most polluted households who exhibit a $40 \%$ decrease in PM2.5 concentration levels. For that group, the number of days over the WHO threshold -not to be exceeded more than 3 days per year- decreased by $52 \%$, from 12.4 down to 5.9 days over the study period. This result is in line with the notion that the Information + Personalised Emission Profile treatment helps eliminate "slack" in combustion activities. In contrast, we observed no significant change in indoor air quality for households receiving the Information treatment, suggesting that generic information about the health risks of combustion activities is not sufficient to induce behavioural changes.

Turning to mechanisms, we find that both interventions were successful at increasing the perceived detrimental impact of wood burning and smoking on indoor and outdoor air pollution, and at decreasing declared frequency of wood burning in the future. We find no evidence of an impact on pollution health risk perception, attitudes toward wood burning regulation, pleasure when lighting a fire, or on the intention to change wood burning equipment in the future. Self-reported frequency of combustion activities was not different between the control group and both treatment groups, as well as air quality improvement efforts, which is at odds with the objective reduction in PM2.5 concentration measured by the micro-monitors. Our interpretation is that self-reported combustion and air quality improvement efforts are not precise enough to capture the behavioural changes that 
happened in the households and did lead to a decrease in PM2.5 concentration. Interestingly, both generic and personalised information were efficient at improving knowledge of the risks associated with combustion activities, but only personalised information induced actual behavioural changes. This finding suggests that pure knowledge and awareness is not sufficient to change behaviour, and that the combination of real-time feedback and social comparison is a powerful lever to overcome remaining obstacles such as inattention and biased beliefs about one's own emission profile.

Our paper makes several contributions to the literature. First, it adds to the limited evidence on the use of smart meters to change behaviours. The originality of smart meters is that they provide real-time, accurate, high-frequency data on one's energy consumption or emission profile, which may be an effective way to overcome inattention and imperfect information recollection by making the implications of one's behaviour salient. However, rigorous evidence on the actual effectiveness of smart meters in changing behaviours is scarce. Buchanan et al. 2015 were concerned that the UK government required energy suppliers to install smart meters in every home as a way to allow consumers to monitor both their electricity and gas consumption, despite the lack of evidence on the contribution of meter readings to energy savings. Since then, two sets of trials have been published showing positive effects of smart meters on behaviours. First, Tiefenbeck, Goette, et al. 2018 and Tiefenbeck, Wörner, et al. 2019 show that providing people with real-time water consumption while showering reduces water consumption by $11 \%$ in hotel rooms and by $22 \%$ at home. Second, Hovell et al. 2020 and S. C. Hughes et al. 2018 show that immediate light and sound alerts from air particle monitors when concentration gets above a given threshold reduces indoor smoking and particle peaks. Our paper innovates by providing the first experimental evidence on the effectiveness of air quality micro-monitor technology in reducing PM2.5 emissions. ${ }^{1}$. It adds to the nascent literature showing how new technologies in our everyday lives can help individuals improve their behaviour by providing more information to households.

Second, our paper contributes to the literature on the effectiveness of information provision in shifting behaviour by specifically comparing the effectiveness of generic versus personalised information. A number of studies have shown that information provision can effectively lead to the adoption of desired behaviours (Jensen 2010; Dupas et al. 2018; Allcott 2011) but meta-analyses generally find great heterogeneity in the effectiveness of information provision (Andor et al. 2018; Karlin et al. 2015), which suggests that the content and format of information matter a lot for effectiveness. Therefore, the key question for policymakers is what

\footnotetext{
${ }^{1}$ Some studies suggest that micro-monitors detecting ambient PM2.5 may help change behaviour but these studies do not use rigorous experimental methods (N. Klepeis, S. Hughes, et al. 2013; Wong-Parodi et al. 2018; Heydon et al. 2020; Iribagiza et al. 2020)
} 
information is most effective in changing behaviour. In a review of thirty-eight interventions to encourage energy conservation, Abrahamse et al. (2005) conclude that generic information alone tends to result in higher knowledge levels but not necessarily in behavioural changes. However, more recent experimental papers have shown that generic information alone can be effective in changing behaviour (Dupas 2011; Dupas et al. 2018; Jensen 2010; Hine, Bhullar, et al. 2011). Other papers show that personalised information can also be effective, be it social comparisons (Allcott 2011; Allcott and Rogers 2014; Ayres et al. 2013) or tailored feedback and advice (Karlin et al. 2015; Abrahamse et al. 2007; Madajewicz et al. 2007; Jalan et al. 2008). But very few studies compare one against the other, and both against no information, as we do in this paper. Notable exceptions are Ferraro, Miranda, et al. (2011) and Ferraro and Price (2013) who show that technical advice on water conservation had no impact on household conservation behaviour unless messages were augmented to include pro-social messages and social comparisons, the latter being the most efficient piece of information with lasting effects. Goldstein et al. (2008) compares the effectiveness of social norm versus environmental protection messages in encouraging towel re-use in hotels, and find that social norms messages induce larger behavioural responses. Finally, De Vries et al. (2008) and CelisMorales et al. (2017) show that receiving personalised feedback and advice on diet and physical activities improves health relative to generic information.

Our paper adds to this literature by testing two different information contents against a control group and comparing their relative effectiveness. We show that generic information is not enough to shift behaviour; although both the Information and Information + Personalised Emission Profile groups received similar information on indoor pollution sources and its detrimental impact on health, only households receiving personalised air quality meter readings changed their behaviour and decreased their indoor pollution. This result further adds to the literature on the awareness-behaviour gap, whereby individuals are aware of an issue, like climate change, air pollution, or the importance of preventive behaviours, but fail to implement concrete actions to curb the issue (Gifford et al. 2011; Kennedy et al. 2004; Schwarzer 2008). Our paper shows that this gap can be reduced by providing individuals with accurate real-time information on their emission profile and social comparisons. These results may be of particular interest for policymakers in a context where micro-sensor technologies that detect ambient PM2.5 levels are increasingly available and affordable (Jiang et al. 2011).

One limitation of our paper relates to its external validity. We focus on voluntary households and on households who rely on wood burning as a complementary (and not primary) heating source. Households who volunteer to be part of a study on air pollution are probably more interested in air pollution than the general 
population. Our sample is also more educated and wealthier than the national average, and exhibit lower levels of indoor air pollution. This may affect treatment effects both upwards or downwards, either because volunteering households might be more willing to change, which would inflate the impact of our intervention, or because they might have already implemented many pollution-reduction strategies, which would decrease the impact of our intervention. This paper can thus pave the way for replications on more representative samples.

The paper is organized as follows. Section 2 describes the context on air quality and wood burning in Île-de-France and details the intervention and experimental design. Section 3 presents our data, outcomes of interest and sample. Section 4 examines the validity of the experiment and presents the estimation method. Section 5 provides the results on indoor air quality, and section 6 the results on knowledge, attitudes and self-reported behaviour. Section 7 concludes.

\section{Context and experimental design}

\subsection{Air quality and wood burning in Île-de-France}

Knowledge and perceptions on indoor air quality Despite being an important health hazard in France, there is limited awareness of indoor air pollution, its sources and its health impacts. The Indoor Air Quality Observatory estimates that 34\% of French dwellings register unsafe levels of PM2.5 (OQAI, 2005) and an estimated cost of $€ 19$ billion per year is attributed to indoor air pollution alone, including for example $€ 1$ billion in asthma medication reimbursement costs (Boulanger et al. 2017). Yet, while almost $90 \%$ of residents in the Île-de-France region ${ }^{2}$ believe that outdoor air pollution presents a major health risk, less than $50 \%$ believe so about indoor air pollution (Menard et al. 2008) and overestimate indoor air quality (Langer et al. 2017). In fact, households still show limited understanding of the different sources of indoor pollution and underestimate its associated sanitary risks (Grange et al. 2012; Daniel et al. 2020). For example, although burning incense and candles can release up to 10 times more PM2.5 than a cigarette, $68 \%$ of candle users and $58 \%$ of incense users stated that this practice has no effect on or even improves indoor air quality (Nicolas et al. 2017; Tirler et al. 2015; Stabile et al. 2012; Andersen et al. 2006).

Wood burning: use and perceptions Wood burning is another major source of PM2.5 both inside users' homes and in the region's ambient air, but a large fraction of this pollution is avoidable. A 2014 report by the Agency for the Environment

\footnotetext{
${ }^{2}$ Île-de-France (Paris and its suburbs) is the most populated of the eighteen regions of France and is centred around the capital Paris, in the north-central part of the country.
} 
and Energy Management (ADEME) estimates that 16\% of households in the Ilede-France region, which amounts to about 79,8000 households, report owning a wood burning equipment. But contrary to users in low- or middle-income countries that rely on wood combustion for heating and cooking (Gordon et al. 2014), the vast majority of households (83\%) use wood burning as an auxiliary or occasional heating source. Besides, most users have not invested in efficient wood burning equipment and have insufficient knowledge of good wood burning practices (ADEME 2015), which leads to higher levels of indoor pollution (Chafe et al. 2015). Given that the region is densely populated, occasional wood burning using old equipment by a minority of households generates a great amount of outdoor pollution and is responsible for more than one third of fine particle emissions in the region's ambient air during winter. Given that wood burning is not a primary source of heating for a sizeable fraction of users, the use of wood burning could be curbed or eliminated with little to no adjustment to the budget of these households.

However, little awareness of the negative health impacts of wood burning results in low effectiveness and acceptability of environmental policy measures. For instance, a $€ 1,000$ subsidy was introduced by the regional authorities in 2018 to replace old equipment by less polluting ones, but the take-up was only $2 \%$. This is not surprising considering that only $21 \%$ of occasional users believe that wood burning has an impact on indoor air quality, a proportion that drops to $16 \%$ when it comes to outdoor air quality. Regarding prohibition policies, $48 \%$ of users report that they would not respect a ban if it were to be implemented (BVA/ADEME, 2014). In fact, a ban on wood burning by the City of Paris in 2014 was faced with intense public and political backlash, leading to a lift of the ban by the Minister of the Environment ${ }^{3}$.

Merely informing users about the dangers of wood burning may thus be an effective strategy in this context. On the other hand, the strong positive feeling associated with wood burning may weaken the effectiveness of informational campaigns. For instance, a recent report shows that, when presented with facts about outdoor pollution caused by wood burning, 30\% of occasional wood burning households do not believe the figures (BVA/ADEME, 2014). Behavioural personalised interventions may thus be required on top of generic information at reducing wood burning.

\subsection{The interventions}

The goal of the proposed intervention is to examine the effectiveness of air quality information in limiting household polluting activities and enhancing indoor air

\footnotetext{
${ }^{3}$ Laetitia Van Eeckhout. "Pourquoi Ségolène Royal veut revenir sur l'interdiction des feux de cheminée en Île-de-France. Le Monde. December 2014. https://www.lemonde.fr/planete/article/2014/12/09/segolene-royaleveut-revenir-sur-l-interdiction-des-feux-de-cheminees_4536996_3244.html
} 
quality. The intervention was developed by researchers in economics and psychology, in collaboration with the Interministerial Directorate for Public Transformation (DITP) and the Île-de-France Regional and Intergovernmental Department of Environment and Energy (DRIEE). The intervention involved mailing eight leaflets ${ }^{45}$ between January and March 2020. All households participating in the study were equipped with air quality monitors. In order to disentangle the impact of personalised feedback from generic information provision, we implemented two treatments.

The Information Treatment In the Information treatment, we sent households informational leaflets about PM2.5 emitting activities, their associated health risks, as well as tips to improve indoor air quality. Each leaflet was composed of a cover page containing an illustration and a catchy slogan, a page containing infographics on sources of indoor air pollution and health risks, and a page providing good practices. The focus, the cover, and the messages were different is each wave. We put an emphasis on wood burning in the last five waves of the intervention (weeks 4 to 8) to overcome households' low awareness of the negative effects of wood burning. The positive image of wood burning was challenged by matching the pollution produced by wood burning to that of other sources that are already perceived as detrimental, such as cigarettes and car exhausts. Framing the impact of wood burning as a direct threat to users, by focusing on indoor rather than outdoor air pollution, is inspired by a large body of research demonstrating that communication of environmental issues is more successful at changing behaviour when presented in a public health frame rather than an environmental or monetary cost frame (Pelletier et al. 2008; Asensio et al. 2016; Cardwell et al. 2013; Myers et al. 2012).

The Information + Personalised Emission Profile Treatment The second treatment provided households with the same generic information as in the Information Treatment, but added people's Personalised Emission Profile based on their real PM2.5 emissions over the previous week. Using data from the air quality monitors, the households' indoor PM2.5 concentration was measured every 5 minutes and represented on a figure along with the date and time of the major pollution peaks. The Personalised Emission Profile also included a ranking of the household in terms of air quality compared to households in the control group. Providing users with their Personalised Emission Profile can alter household polluting behaviour through four different channels. First, the graphs help households identify pollution peaks that occurred in the previous week and encourage them to link these peaks to domestic activities, which provides a better understanding and management of

\footnotetext{
${ }^{4}$ The first two leaflets were sent two weeks apart, while the following six were sent every week.

${ }^{5}$ All materials can be found in the online appendix: https://osf.io/5br8y/
} 
indoor air quality. Second, as pollutants are invisible to the human eye (Gee et al. 2013) and their costs on health are often delayed, the graphs can help households overcome salience issues and temporal discounting by making the intangible aspect of pollution visible in the present. Third, the personalised statements could reinforce the overall credibility of the generic information. Finally, the use of social comparison may stimulate behavioural change.

\subsection{Experimental design}

To measure the differential effect of each treatment, 281 households received a micro air quality monitor and were assigned to the control group, the Information treatment, or the Information + Personalised Emission Profile treatment. Using a baseline questionnaire, households were stratified by the presence of a smoker in the household and then matched into the best triplets according to their average weekly PM2.5 levels at baseline ${ }^{6}$. This resulted in 94 triplets. Within each triplet, households were randomly assigned to one of the 3 groups. At the end of the intervention, the control households were given access to the informational campaign, and both the Information and control groups received their indoor air quality Personalised Emission Profile for the entire intervention period.

\section{Data and Sampling}

\subsection{Data sources and outcomes of interest}

\subsubsection{Micro-monitor indoor pollution data}

Every household was equipped with a micro-monitor that retrieved PM2.5, PM10, temperature and humidity levels every five minutes and transmitted it to an online platform set up by the manufacturer, using the 2G Network. Participating households were asked to place the monitor no closer than $1 \mathrm{~m}$ and no farther than $4 \mathrm{~m}$ away from their wood burning equipment. In order to minimise the experimenter demand effect, the chosen micro-monitors ${ }^{7}$ are discrete, small, and provide no visible indications about the measured air quality.

The micro-monitor thus had two functions; it served as an intervention instrument, allowing us to send personalised summaries of air quality in the Information + Personalised Emission Profile group, as well as a reliable way to measure the impact of the intervention, given that the difference in indoor pollution between each treatment group and the control group is the most consistent and reliable indicator of change in household behaviour.

\footnotetext{
${ }^{6}$ Both smoking and baseline indoor PM2.5 levels highly predict indoor air pollution post-treatment

${ }^{7}$ Atmotrack Atm01 by 42 Factory: https://atmotrack.fr/
} 
Following our main pre-registered hypothesis, we expect that the intervention will have an impact on household's PM2.5 emission profiles. Our main outcome of interest is households' average daily PM2.5 level over the whole post-treatment period. Another outcome of interest is the number of days a household registered higher PM2.5 levels than the WHO 24hrs guidelines (over $25 \mu \mathrm{g} / \mathrm{m}^{3}$ ).

\subsubsection{Self-reported questionnaire data}

Households completed one online questionnaire at baseline and one at endline. Baseline data were collected from August to December 2019. The endline questionnaire was administered at the end of March 2020, 3 weeks after the end of the intervention. The endline questionnaire measured three types of outcomes to look at the mechanisms of change in indoor air quality between the three groups.

Perception and knowledge about air pollution The baseline and endline questionnaires included questions about the household's perceived indoor and outdoor air quality, knowledge of main indoor and outdoor sources of pollution, and perceived impact of air pollution on health.

Perception, knowledge and attitude about wood burning The baseline and endline questionnaires included a set of variables reflecting the household's perception on the contribution of wood burning to indoor pollution, knowledge of good wood burning practices, attitude towards wood burning regulation, pleasure when lighting a fire, as well as the intention to change wood burning equipment in the future.

Self-reported polluting activities We collected information about households' selfreported polluting activities, such as the number of times they engaged into smoking, wood burning, candles, incense, and dusting over the past week; overall frequency of wood burning over the past winter, and intended use in the future.

The baseline questionnaire also collected information about the household's socioeconomic and demographic characteristics (age and educational level of the respondent, monthly household income, number of residents), self-reported health status (subjective health status, the presence of a person with respiratory problems in the household, investment in health, the presence of a smoker in the household), environmental beliefs and attitudes, and type of wood burning equipment. See online appendix for a full list of baseline and endline questions.

\subsection{Sampling strategy and sample characteristics}

The experiment was presented on a website where applicants could volunteer to install an air quality micro-monitor in their homes for six months and receive 
information on ways to decrease indoor pollution. Participants who wished to be part of the study were asked to fill out the recruitment survey, which also served as the baseline questionnaire. The call for volunteers was advertised through multiple channels : first, the Regional and Intergovernmental Department of the Environment and Energy passed on our call for volunteers to local communities, authorities, and institutions. Second, we emailed a list of households identified as wood burning households by the Agency for the Environment and Energy Management. Finally, we relied on a collaborative network of brands and consumers, "Wedoolink". A total of 4,200 people volunteered to take part in the study. Within this sample, 558 people used wood burning, of whom 370 reported using wood burning as an occasional heating method. Only these households were included in the study, whereas those using wood burning as their only source of heating were excluded. We chose to restrict the study sample to households that burn wood occasionally for two main reasons: first, when a household's main heating source is wood burning, a change in behaviour is constrained by multiple barriers, including financial ones; second, the primary aim of the intervention was to limit avoidable burning of wood. Due to technical issues related to the strength of the $2 \mathrm{G}$ signal, 36 households could not be included because their micro-monitor did not transmit data consistently. We also asked participants to tell us whether they knew people taking part in the study and identified 13 clusters of "friends". In order to avoid spillovers, only one individual in each cluster was randomly included in the study. The final sample included 281 households, mostly residents of the Ile-de-France region.

Column 1 in Table 1 presents the characteristics of the households at baseline. The sample characteristics are comparable to those of the population of occasional users of wood burning in the Île-de-France region (BVA / ADEME, 2015), which means that it is not representative of the entire French population. Respondents have a mean age of 49 years, they are highly educated ( $46 \%$ have a Masters degree or more), and they are of middle-high to high income status (80\% earn more than $€ 3400$ per month). In the sample, air quality at home is wrongly perceived as being better than air quality in the neighbourhood, which is itself perceived as better than the air quality of the entire Île-de-France region. Regarding wood burning, 55\% of respondents believe it to be an important source of outdoor pollution, and $36 \%$ list it as an important source of indoor pollution. Half of the households use wood burning more than once a week, $32 \%$ use it more than once a month, and $17 \%$ use it once a month or less. The baseline picture thus shows large margins of improvement in households' knowledge and behaviour. 


\section{Validity of the experiment and estimation method}

\subsection{Validity of the experiment}

Balance checks Table 1 presents balance tests of household characteristics across treatment arms. We found some imbalances in the Environmental Attitudes score and respiratory problems in the household between the Information treatment and control groups, the perception of air quality in the region between both treatment groups and the control group, and the type of equipment between the Information treatment and control groups as well as between the Information and the Information + Personalised Emission Profile treatment groups. We found eight significant differences in means out of a total of 81 tests, which is exactly what we expect under the hypothesis that all groups are drawn from identical underlying distributions and that differences are purely due to chance sampling fluctuations. The balance checks did not reject the assumption that each treatment group is statistically identical to the control group. We ran the analyses both including and excluding these variables as controls and found qualitatively and quantitatively similar estimates across specifications, which suggests that the bias introduced by these baseline differences do not account for our results.

Attrition There was no attrition for indoor air quality monitor data. Attrition was very small at endline $(4.6 \%)$ and was evenly distributed across the three groups ${ }^{8}$.

\subsection{Estimation method}

\subsubsection{Indoor air quality}

We measured the Average Treatment Effects of both interventions on indoor air quality by running the following regression:

$$
Y_{i, j, p o s t}=\alpha+\beta T_{1, i}+\gamma T_{2, i}+\theta_{j}+\epsilon_{i, j}
$$

where $Y_{i, j, p o s t}$ represents the outcomes of interest for household $i$ in triplet $j, T_{1, i}$ is a dummy indicating that the household is in the Information group, $T_{2, i}$ is a dummy indicating that the household is in the Information + Personalised Emission Profile group, $\theta_{j}$ is a vector of triplet fixed effects aimed at reducing the variance of the treatment effect estimators (Abadie et al. 2017), and $\epsilon_{i, j}$ is the heteroscedasticity robust error term.

To exploit longitudinal variations in indoor PM2.5 levels, we estimated how the treatment effect varied over the 3-month intervention period. The permanency of behavioural changes following information campaigns is often questioned, as the

\footnotetext{
${ }^{8} \mathrm{~A}$ linear probability model regression failed to reject the null hypothesis that the probability of having baseline data was similar between the three groups. Results are shown in the Appendix Table A1
} 
effect is expected to be concentrated in the "hot phase" of decision making, the first weeks following the beginning of the intervention, but might then decay as the novelty effect dissipates (Allcott and Rogers 2014; Ferraro and Price 2013; Gneezy et al. 2006). By contrast, the intervention could alter beliefs and attitudes and lead to long-lasting behavioural changes. To capture the short-run dynamics of the effect, we interacted both treatment variables $T_{1, i}$ and $T_{2, i}$ with a set of weekly indicator variables $W_{k}$, with $k$ denoting the week since the start of the intervention:

$$
Y_{i, j, k}=\alpha+\sum_{k=-2}^{11} \beta_{k} T_{1, i} W_{k}+\sum_{k=-2}^{11} \gamma_{k} T_{2, i} W_{k}+\sum_{k=-2}^{11} W_{k}+\theta_{j}+\epsilon_{i, j, k}
$$

$\epsilon_{i, j, k}$ is clustered at the household level and at the week level, and robust to heteroscedasticity. $\beta_{k}$ thus provides the impact of Information treatment in week $k$, while $\gamma_{k}$ provides the impact of Information + Personalised Emission Profile in week $k$.

\subsubsection{Heterogenous treatment effects}

As intended in the pre-analysis plan, we tested whether treatment effects were different depending on the initial level of PM2.5 emission. On the one hand, people with a high baseline level of PM2.5 emission may be more likely to respond to the interventions as there is more room for change. On the other hand, their high emission profile may reflect constraints that render their beliefs and behaviour more persistent (e.g., less education, lower income, or lower level of trust). Theoretically, how the initial level of PM2.5 emission affects treatment effects is thus ambiguous. To test it, we added dummy variables indicating the quartile of baseline PM2.5 level, as well as the interaction between each of these dummies and the treatment variables.

We also hypothesised that the impact might vary as a function of outdoor temperatures. While on very cold days, a household has to use wood burning for complementary heating, on warmer days the use of wood burning is more likely to be limited to recreational purposes, leading to a larger margin of improvement. To that end, we used household daily outdoor temperature and interacted the treatment variables with three temperature categories: cold days ( $<8$ degree $\mathrm{C}$ ), moderate days ( between 8 and 14 degrees) and warm days (more than 14 degrees). Outside local temperature levels were retrieved from the official public administrative institution of meteorology and climatology in France ("Météo France"). The daily temperature was assigned to each household based on the closest meteorological station available. 


\subsubsection{Mechanisms}

To measure the treatment effects on outcomes measured in the endline questionnaire, we used an OLS regression without including triplet fixed effect in order to avoid a loss of observations and statistical power due to attrition in the endline questionnaire:

$$
Y_{i, p o s t}=\alpha^{\prime}+\beta^{\prime} T_{1, i}+\gamma^{\prime} T_{2, i}+\epsilon_{i}^{\prime}
$$

\section{Impacts on indoor air quality}

\subsection{Average treatment effect}

Table 2 presents the impact of the interventions on indoor air quality. Column (1) shows the ATE estimates on average daily PM2.5 level over the whole posttreatment period using the main specification (equation 1). While the Information treatment led to a non-significant $0.19 \mathrm{\mu g} / \mathrm{m}^{3}$ decrease in average daily PM2.5, the Information + Personalised Emission Profile treatment induced a significant 1.315 $\mathrm{\mu g} / \mathrm{m}^{3}$ decrease in average daily PM2.5 over the post-treatment period, representing a $24 \%$ decrease relative to the control group mean. This was robust to the inclusion of controls to correct for baseline imbalances (Column 2): the reduction in average daily PM2.5 is $0.03 \mu \mathrm{g} / \mathrm{m}^{3}$ (non significant) for the Information treatment and 1.175 (significant at the 1\% level) for the Information + Personalised Emission Profile treatment. Based on these estimates, the Information treatment appears 2.6 more cost-effective than the Information treatment. ${ }^{9}$

Figure 1 provides insights on the dynamics of the impact across time: it displays the ATE estimates interacted with dummies indicating the number of weeks since the first message, after adjustment for triplet and week fixed effects (equation 2). While the households receiving the Information treatment show no difference in indoor air quality compared to the control group in any week throughout the whole intervention period, the Information + Personalised Emission Profile intervention started to have an impact on polluting behaviour rather fast: the effect is significant starting the third week after the start of the intervention and is persistent throughout weeks 5, 6 and 8 of the intervention, and weeks 10 and 11 after the end of the intervention. There is no noticeable decay of the effect throughout the 3 months of treatment - if anything rather an amplification, indicating that there was no habituation effect to the novelty of the messages or to the monitor.

\footnotetext{
${ }^{9}$ The Information + Personalised Emission Profile treatment's cost is 15 times larger, and its impact 39 times larger, than the Information treatment.
} 
Figure 1: Average treatment effects on Indoor daily PM2.5 levels, by week since the first message

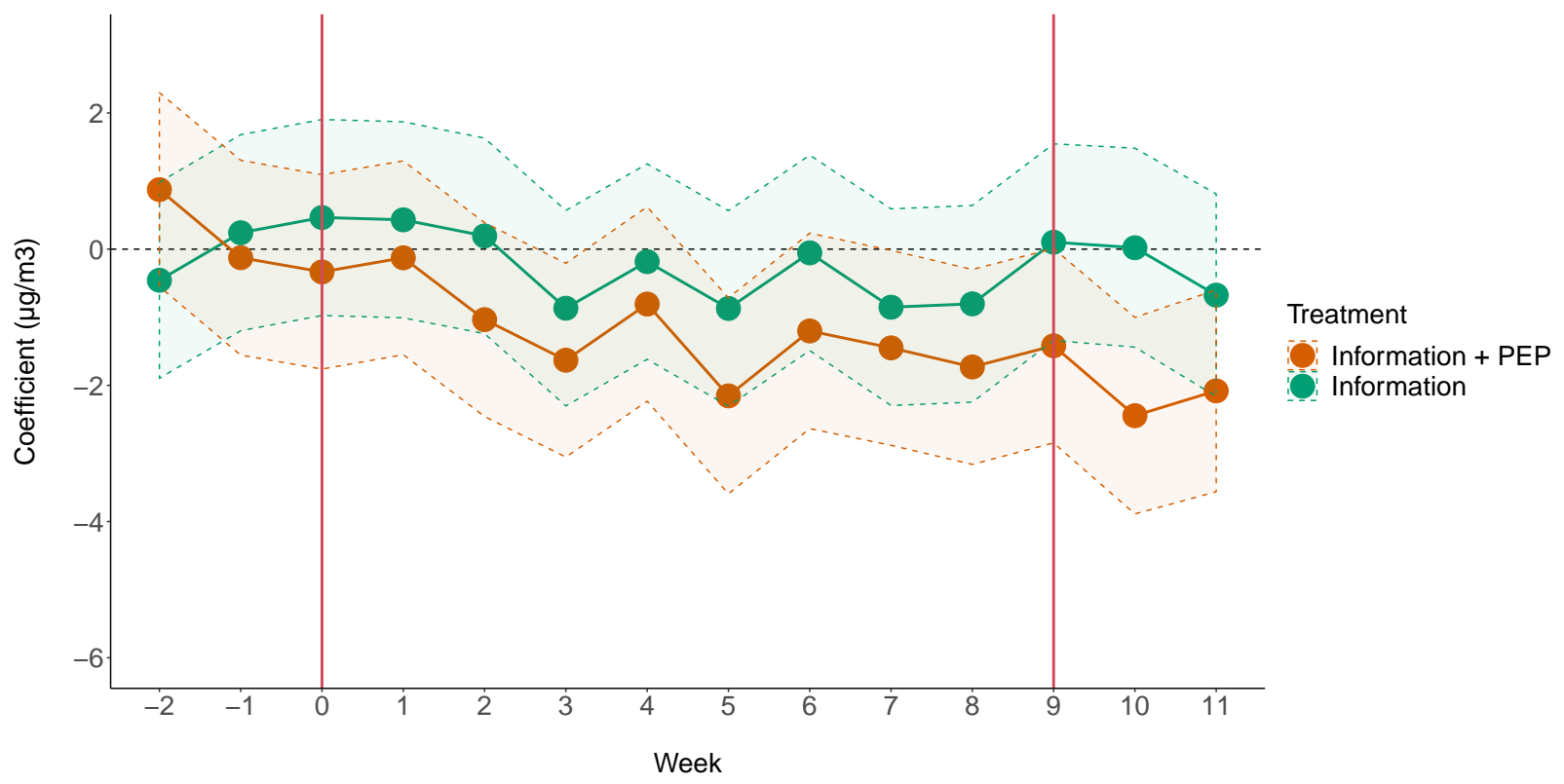

Notes: Confidence intervals are computed at the $95 \%$ confidence level. The figure represents the coefficients on the interaction between each intervention dummy and weekly dummies. Triplet and weekly fixed effects are included. Standard errors are clustered at the household and week levels. The two solid vertical lines represent the start and the end of the intervention. Week 0 starts on January 6th 2020, when the first message was sent the participants in the Information and Information + Personalised Emission Profile. The last message was sent on the 9th of March 2020 , on week 9 .

\section{$5.2 \quad$ Heterogeneous effects}

In this section, we tested whether the effectiveness of the intervention depends on the household's initial level of pollution and on outside temperature.

Initial level of pollution In line with other personalised feedback and social comparison interventions (Allcott 2011; Ferraro and Price 2013; Schultz et al. 2007), the households that were more polluted to begin with responded more to the Information + Personalised Emission Profile intervention. Table 3 shows the treatment effect by quartile of baseline PM2.5 concentration. The treatment effect of the Information + Personalised Emission Profile intervention was concentrated in households in the 4th quartile of baseline PM2.5 concentration, i.e. the highest polluters. In that group, the Information + Personalised Emission Profile intervention decreased indoor PM2.5 levels by $4.9 \mu \mathrm{g} / \mathrm{m}^{3}$, a $36 \%$ decrease compared to the control group mean, significant at the $95 \%$ confidence level. These households are less affluent, reported the presence of a smoker and using wood burning equipment more frequently and reported a better subjective health status (see Appendix Table A2). Households in the third quartile receiving the Information treatment decrease their indoor pollution by $18 \%\left(-0.78 \mu \mathrm{g} / \mathrm{m}^{3}\right)$. This decrease was only significant at the $10 \%$ level and was much smaller in absolute size. While the effect was not significantly different than 0 in the households with 
the best indoor air quality, the boomerang effect found in other normative feedback experiments, which leads households that are better than average to pollute more, was not found here (Ayres et al. 2013; Schultz et al. 2007).

Figure 2 shows the dynamics of the treatment effect (equation 2) by quartile of baseline indoor pollution level. Regarding households exposed to the Information treatment, there was no significant difference relative to the control group for any quartile of baseline level of pollution. In contrast, regarding households exposed to the Information + Personalised Emission Profile intervention, the treatment effect is significant for the highest quartile of baseline indoor pollution every week starting the second week after the reception of the first leaflet.

Outside temperature levels Table 4 shows the estimates of the treatment effect on daily levels of indoor PM2.5, on three different sub-samples: days where the household's municipality recorded an outside temperature lower than $8^{\circ} \mathrm{C}$ (cold days), between 8 and $14^{\circ} \mathrm{C}$ (moderate days) or above $14^{\circ} \mathrm{C}$ (warm days). While there was a significant treatment effect of the Information + Personalised Emission Profile intervention on cold and moderate days, with a bigger effect on moderate days $\left(-1.3 \mu \mathrm{g} / \mathrm{m}^{3}, \mathrm{p}<0.01\right)$, the treatment effect was not significant on warmer days. It is worth noting, however, that there were far fewer days with a temperature above $14^{\circ} \mathrm{C}$ leading to lower statistical power. Overall, the differences in ATE between cold, moderate and warm days were not statistically significant (see Table 4).

\subsection{Number of days over the WHO 24-hour guideline}

Another outcome of interest is the number of days a household was exposed to extremely dangerous levels of pollutants. The WHO guidelines on PM2.5 24-hour exposure is $25 \mathrm{\mu g} / \mathrm{m}^{3}$ not to be exceeded more than 3 days a year. Table 5 reports the average treatment effect of the interventions on the number of days exceeding this threshold over the study period, i.e., 77 days. Note that in the control group, the average number of days above the threshold was 2.9 days over four months only, thus well above the WHO recommendation. There was no impact of the Information treatment, which confirms that this intervention was insufficient to induce a change in behaviour. In contrast, the Information + Personalised Emission Profile treatment reduced the number of days exceeding the WHO threshold by 1.44 days, a $50 \%$ decrease compared to the control group mean, significant at the $10 \%$ level (Table 5, Column 1). The effect is greatly heterogeneous as it concentrates only on the most polluted households (4th quartile of baseline PM2.5 concentration): for these households, the Information + Personalised Emission Profile treatment induced a decrease of days above the WHO threshold from 12.4 days down to 5.9 days over a period of four months, a change significant at the $5 \%$ level (Table 5, Column 
Figure 2: Average treatment effect on Indoor PM2.5 levels, by week and quartile of baseline PM2.5

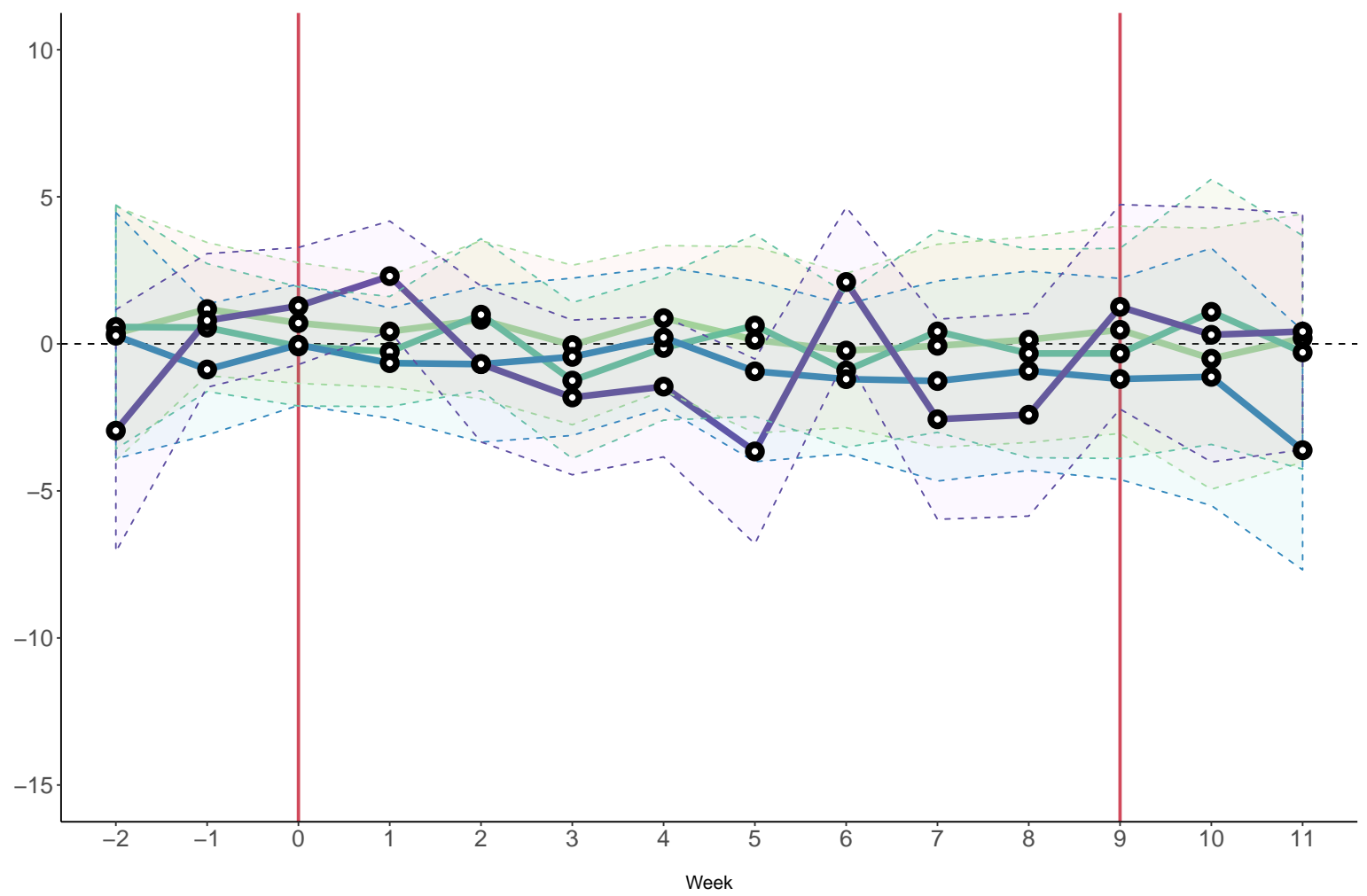

(a) Information treatment

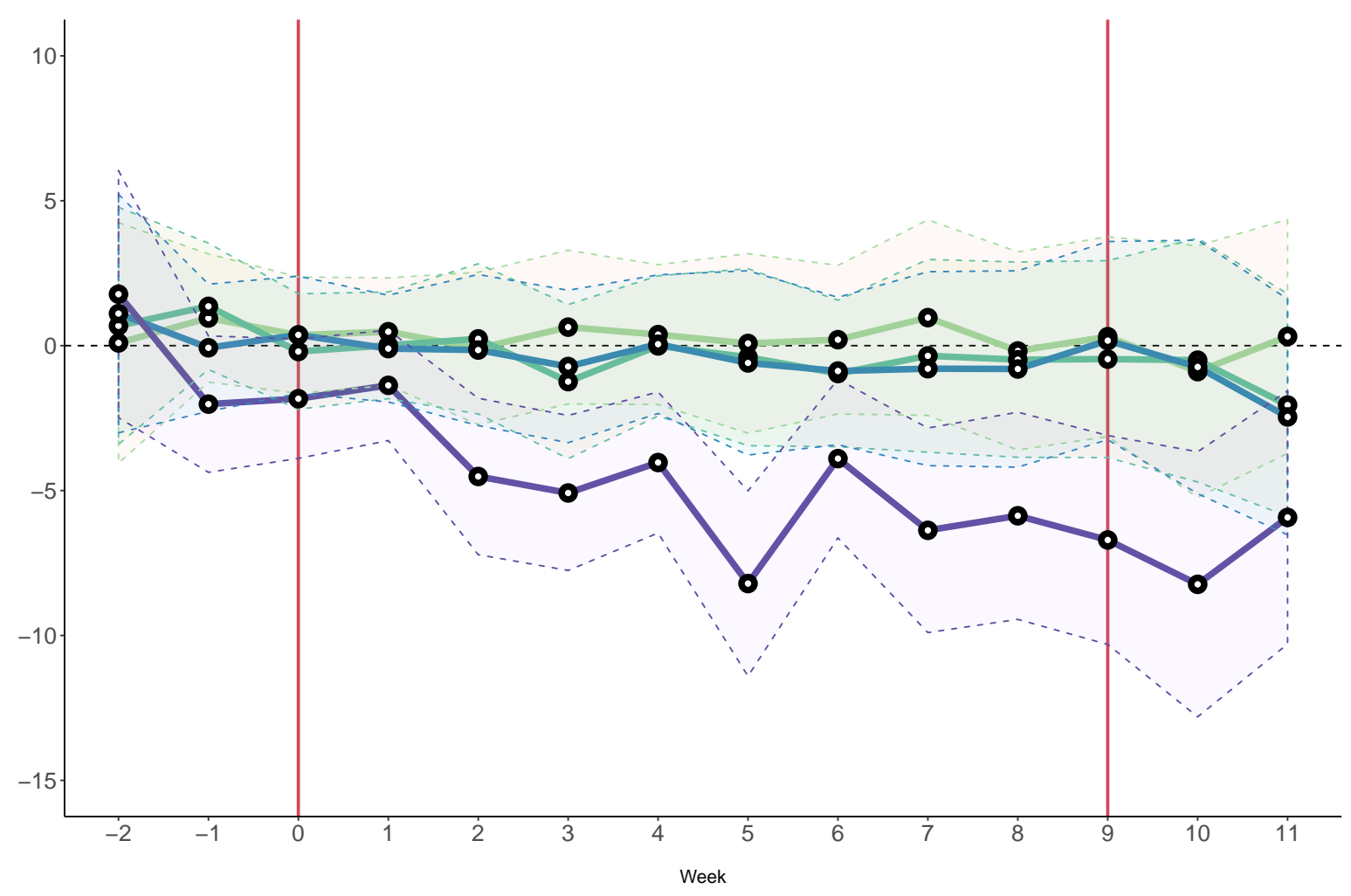

Quartiles of baseline indoor PM2.5

- Quartile 1

- Quartile 2

- Quartile 3

- Quartile 4

(b) Information + Personalised Emission Profile treatment

Notes: Confidence intervals are computed at the $95 \%$ confidence level. The figure represents the coefficients on the interaction between each intervention dummy and weekly dummies. Triplet and weekly fixed effects are included. Standard errors are clustered at the household and week levels. The two solid vertical lines represent the start and the end of the intervention. Week 0 starts on January 6th 2020, when the first message was sent the participants in the Information and Information + Personalised Emission Profile. The last message was sent on the 9th of March 2020 , on week 9 . 
5). For the other less polluted households, the number of days above the WHO threshold was already very small and in line with WHO recommendations (0.120.57 days over four months on average), and we see no impact of the treatments. Overall, our data show that the households who responded to and benefited from the intervention were those who needed it the most.

\subsection{Magnitude of the effects and sanitary impacts}

The magnitude of the effect of the Information + Personalised Emission Profile intervention is sizeable, considering that the effect sizes of similar interventions aimed at energy conservation typically vary between 2\% and 20\% (Karlin et al. 2015). From a public health perspective, a decrease of $1.315 \mathrm{\mu g} / \mathrm{m}^{3}$ in average exposure to PM2.5 is also noteworthy. In fact, studies have shown that an increase in exposure of as little as $1 \mathrm{\mu g} / \mathrm{m}^{3}$ can have serious health consequences. For instance, an increase of $1 \mathrm{\mu g} / \mathrm{m}^{3}$ in PM2.5 was associated with a dementia incidence of a 1.55 hazard ratio (Oudin et al. 2018) and an 11\% increase in COVID-19 mortality rates (Wu et al. 2020). A review on Medicare patients in the U.S. showed that an increase in short-term exposure to PM2.5 of $1 \mu \mathrm{g} / \mathrm{m}^{3}$ is associated with an annual increase of 3,642 hospital admissions, 20,000 extra hospitalisation days and almost $\$ 70 \mathrm{~m}$ in care cost at the country level (Wei et al. 2019). The sanitary impacts are even more important for the most polluted households where the Information + Personalised Emission Profile intervention led to a decrease in average daily PM2.5 levels of 4.9 $\mu \mathrm{g} / \mathrm{m}^{3}$. In fact, an improvement in PM2.5 exposure of $5 \mathrm{\mu g} / \mathrm{m}^{3}$ is associated with a $16 \%$ decreased incidence of hypertension and the total annual economic benefits of decrease of ambient air pollution by $5 \mu \mathrm{g} / \mathrm{m}^{3}$ in Paris is estimated to be around $€ 3.6$ billion, including reductions in health spending, productivity loss and immaterial costs namely quality of life and life-expectancy (Pascal et al. 2013).

\section{Mechanisms}

\subsection{Knowledge about indoor PM2.5 sources}

The interventions provided information on the different sources of PM2.5. Table 6 displays treatment impact on the probability of correctly citing different indoor PM2.5 emitting sources. Both treatments led to an important increase in the probability of reporting wood burning and cigarette smoking as a main source of indoor PM2.5; households that received the Information + Personalised Emission Profile were $50 \%$ and $136 \%$ more likely to cite wood burning and cigarette smoking compared to the control group. The Information treatment led to a similar increase in the reporting of wood burning as a main source of PM2.5, and an increase of $100 \%$ when it comes to cigarettes, though only significant at the $10 \%$ level. 
Conversely, neither the Information nor the Information + Personalised Emission Profile increased the probability of citing candles, incense and cooking as major indoor PM2.5 sources. This absence of impact is not explained by perfect knowledge of these combustion activities as major sources of pollution, as less than only 4 to 9 percent of households mention candles, incense, and cooking in the control group. Awareness of the risks associated with wood burning and smoking were already more salient and further increased thanks to the intervention.

\subsection{Beliefs, knowledge, and attitude about wood burning pollution}

The intervention provided information on the health and environmental risks of PM2.5 emissions with an important focus on wood burning. The top panel of Table 7 details the average treatment effects of both interventions on beliefs, knowledge, and attitudes towards wood burning, while the bottom four panels shows the treatment effect by quartile of baseline PM2.5. Neither the Information nor the Information + Personalised Emission Profile interventions had an impact on the perception of the health risks associated with air pollution (Column 1). In contrast, both interventions increased the perceived negative impact of wood burning on indoor air quality, by 6 points (on a score from 0 to 100) in the Information group (significant at the $10 \%$ level), and by 9 points in the Information + Personalised Emission Profile group (significant at the 1\% level), off a base score of perceived risk of 60 in the control group. This effect was concentrated on the most polluted households (quartile 4), whose baseline perceived risk of wood burning was lower (the control group mean is 53 in quartile 4 versus 59, 65, and 61 in the other quartiles) and was almost twice as big $(\mathrm{p}$-value $=0.05)$ for the Information + Personalised Emission Profile treatment (20-point increase, significant at the $1 \%$ level) as for the Information treatment (12-point increase, significant at the $5 \%$ level). Providing the household with direct information about their indoor PM2.5 profile thus reinforced the overall credibility of the generic messages more in households where pollution is high.

The belief that wood burning is a major source of outdoor pollution also increased in both treatment groups (Column 3): while $45 \%$ of households in the control group believed that wood burning is a major source of outdoor pollution, the intervention increased that proportion by 18.7 points in the Information group and by 14.3 points in the Information + Personalised Emission Profile group. In quartiles 1, 2 and 3 of baseline PM2.5 concentration, the effects were somewhat larger in the Information group than in the Information + Personalised Emission Profile group, whereas the opposite was true in the most polluted households (quartile 4). Estimates are quite imprecise though, and thus marginally significant and not always statistically different one from the other.

The leaflet also provided information on how to decrease PM2.5 in general and 
good practices to decrease emissions from wood burning in particular. Column (4) in Table 7 presents the impact of the interventions on the probability of mentioning one good practice for more efficient wood burning. While $67 \%$ of households in the control group name at least one good wood burning practice, this proportion increased by 13 percentage points in both treatment groups - significant at the $10 \%$ level. The effect was larger in less polluted households (quartiles 1 and 2 of baseline PM2.5), which may be related to lower baseline knowledge of good practices, especially in quartile 2 .

The intervention had no significant impact on households' attitude towards wood burning regulation, the pleasure felt when lighting a fire, or the intention to change wood burning equipment (Columns 5, 6, and 7). Overall, these results show that both interventions improved awareness of the role of wood burning in generating PM2.5 pollution and good practices to reduce pollution. These positive effects were not restricted to a particular group of households, although some effects were particularly pronounced for most polluted households in the Information + Personalised Emission Profile group.

\subsection{Self-reported polluting activities}

Wood burning We asked households about the frequency of use of wood burning this past winter, and their intended frequency of use in the future. Table 8 shows the results of the declared frequency of use regressed on the two treatment dummies, controlling for baseline frequency. We found no difference in the frequency of use of wood burning throughout the treatment period. However, both treated groups reported that they intended to decrease wood burning in the future. Compared to the control group, households exposed to Information or Information + Personalised Emission Profile were 12 percentage points less likely to declare that they intended to use wood burning "Once a week or less" next winter (a 25\% increase from 48\%, significant at the $1 \%$ level). This effect seems to concentrate in households in the second quartile of baseline indoor pollution. In the endline questionnaire, we also asked "How many times in the last week have you used wood burning?". The treatment effects on this variable is shown in Column 1 of Table 9.

Other activity affecting air quality The declared frequency of other PM2.5 emitting activities did not differ significantly between the three groups. Households receiving weekly messages were not different from the control households in their declared frequency of use of electronic and tobacco cigarettes, candles, incense or dusting (Table 9). Similarly, we found no significant change in the declared frequency of activities that improve indoor air quality (Table 10). Similarly, we found no change on the extensive margin of polluting and air quality enhancing activities (Tables 11 
and 12).

Interpretation Self-reported polluting activities were not affected by any intervention. This result is at odds with PM2.5 micro-monitor data showing a significant reduction in pollution in the Information + Personalised Emission Profile group. The discrepancy between objective PM2.5 measures and self-declared polluting activities may be due to the fact that households may not report their behaviour accurately, maybe because of memory issues or social desirability biases. Alternatively, our questions were not precise enough to capture the changes in behaviour. We also found that that self-reported frequency of polluting or air quality improving activities did not predict levels of PM2.5 (Appendix Table A3). A third interpretation is that the decrease in indoor PM2.5 levels is not associated with a decrease in wood burning, a better management of firewood, or a decrease in indoor smoking, incense, and candle, but to better ventilation and wood burning management. Although we observe that the frequency of ventilation has not changed between following the treatment, it is possible that treated households ventilate for a longer or at more appropriate times. Overall, these results highlight the importance of collecting objective, non self-declared, measures in impact evaluations.

\section{Conclusions}

We conducted a randomized field experiment among occasional wood burning households in France to test the effectiveness of generic versus personalised information in decreasing indoor air pollution. We use the difference in the level of PM2.5 inside the home as an objective proxy of household polluting behaviour. Our results suggest that information about the risks associated with combustion activities combined with personalised information on indoor air quality is effective in decreasing polluting activity and improving indoor air, particularly in the most polluted households at baseline. Personalised emission profile and social comparisons could change household behaviour by providing salient direct information that help households update their beliefs and better manage their activity. The improvement in indoor air started the 3rd week after the beginning of the intervention, and did not decay throughout the intervention period as well as two weeks after the end of the intervention.

Another main finding of our study is that while generic information about indoor air pollutants was effective in increasing households' awareness about the negative impacts of woodburning, it was only effective in changing polluting behaviour when augmented with personalised information on indoor air quality. This is 
also consistent with a large body of research documenting the awareness-action gap, whereby greater knowledge about environmental and health issues does not necessarily translate in adequate behaviour (Kollmuss et al. 2002; Rimal 2000). This could be explained by optimism bias, a well documented tendency to underestimate the individual risk of the occurrence of a negative event for oneself (Weinstein 1980), which leads people to believe that they are less at risk than average of suffering various health hazards such as having a heart attack, contracting AIDS, being in a traffic accident or developing cancer (Sharot 2011; Fontaine and Smith 1995; Fontaine 1994; DeJoy 1989; Perloff et al. 1986). This might explain why the generic information was successful in increasing awareness about the emitting sources of wood burning, for example, but was insufficient to shift behaviour. In contrast, sending detailed information about PM2.5 concentrations in participants' own living room could help counter this optimism bias by increasing the salience of the actual risk they are exposed to.

As a concluding note, we would like to emphasize that the external validity of our study is limited and affects the generalisability of our estimated effect size. Households in our sample agreed to install an air quality monitor in order to receive information on their home's air quality as well as recommendations on how to improve it. This means that our sample is likely more sensitive to air quality than the total underlying population, which may have affected the impact of the intervention positively or negatively. The treatment effect will have been overestimated if our households reacted more to the treatment because of their baseline interest in air pollution, or underestimated if our sample's preexisting effort to reduce air pollution decreased their margin of behavioural change compared to a more representative sample. 


\section{References}

Abadie, A., Athey, S., Imbens, G. W., and Wooldridge, J. (2017). When should you adjust standard errors for clustering? Tech. rep. National Bureau of Economic Research.

Abrahamse, W., Steg, L., Vlek, C., and Rothengatter, T. (2005). "A review of intervention studies aimed at household energy conservation". In: Journal of environmental psychology 25.3, pp. 273291.

- (2007). "The effect of tailored information, goal setting, and tailored feedback on household energy use, energy-related behaviors, and behavioral antecedents". In: Journal of environmental psychology 27.4, pp. 265-276.

ADEME (2015). Le chauffage domestique au bois en région Île-de-France. Tech. rep.

Allcott, H. (2011). "Social norms and energy conservation". In: Journal of public Economics 95.9-10, pp. $1082-1095$.

Allcott, H. and Rogers, T. (2014). "The short-run and long-run effects of behavioral interventions: Experimental evidence from energy conservation". In: American Economic Review 104.10, pp. 3003-37.

Amann, M., Cofala, J., Klimot, Z., Nagl, C., and Schieder, W. (2018). "Measures to address air pollution from small combustion sources". In: Clean Air Outlook Combustion Sources Report, European Commission.

Andersen, D. N., Holmberg, D., Larsen, J. R., Søborg, I., and Cohr, K.-H. (2006). "Survey and health assessment of chemical substances in massage oils". In: Survey of chemical substances in consumer products, no. 78.

Andor, M. and Fels, K. M. (2018). "Behavioral Economics and Energy Conservation-A Systematic Review of Non-price Interventions and Their Causal Effects". In: Ecological Economics 148.C, pp. $178-210$.

Asensio, O. I. and Delmas, M. A. (2016). "The dynamics of behavior change: Evidence from energy conservation". In: Journal of Economic Behavior \& Organization 126, pp. 196-212.

Asikainen, A., Carrer, P., Kephalopoulos, S., Oliveira Fernandes, E. de, Wargocki, P., and Hänninen, O. (2016). "Reducing burden of disease from residential indoor air exposures in Europe (HEALTHVENT project)". In: Environmental Health 15.1, pp. 61-72.

Ayres, I., Raseman, S., and Shih, A. (2013). "Evidence from two large field experiments that peer comparison feedback can reduce residential energy usage". In: The Journal of Law, Economics, and Organization 29.5, pp. 992-1022.

Bhullar, N., Hine, D., Marks, A., Davies, C., Scott, J., and Phillips, W. (2014). "The affect heuristic and public support for three types of wood smoke mitigation policies". In: Air Quality, Atmosphere 83 Health 7.3, pp. 347-356.

Boso, A., Hofflinger, A., Oltra, C., Alvarez, B., and Garrido, J. (2018). "Public support for wood smoke mitigation policies in south-central Chile". In: Air Quality, Atmosphere $\& 3$ Health 11.9, pp. 1109-1119.

Boulanger, G., Bayeux, T., Mandin, C., Kirchner, S., Vergriette, B., Pernelet-Joly, V., and Kopp, P. (2017). "Socio-economic costs of indoor air pollution: A tentative estimation for some pollutants of health interest in France". In: Environment international 104, pp. 14-24.

Buchanan, K., Russo, R., and Anderson, B. (2015). "The question of energy reduction: The problem (s) with feedback". In: Energy Policy 77, pp. 89-96.

Burnett, R., Chen, H., Szyszkowicz, M., Fann, N., Hubbell, B., Pope, C. A., Apte, J. S., Brauer, M., Cohen, A., Weichenthal, S., et al. (2018). "Global estimates of mortality associated with long-term exposure to outdoor fine particulate matter". In: Proceedings of the National Academy of Sciences 115.38, pp. 9592-9597. 
Cardwell, F. S. and Elliott, S. J. (2013). "Making the links: do we connect climate change with health? A qualitative case study from Canada". In: BMC public health 13.1, p. 208.

Celis-Morales, C., Livingstone, K. M., Marsaux, C. F., Macready, A. L., Fallaize, R., O’Donovan, C. B., Woolhead, C., Forster, H., Walsh, M. C., Navas-Carretero, S., et al. (2017). "Effect of personalized nutrition on health-related behaviour change: evidence from the Food4me European randomized controlled trial". In: International journal of epidemiology 46.2, pp. 578588.

Chafe, Z., Brauer, M., Héroux, M.-E., Klimont, Z., Lanki, T., Salonen, R. O., and Smith, K. R. (2015). "Residential heating with wood and coal: health impacts and policy options in Europe and North America". In:

Daniel, L., Michot, M., Esvan, M., Guérin, P., Chauvet, G., and Pelé, F. (2020). "Perceptions, Knowledge, and Practices Concerning Indoor Environmental Pollution of Parents or Future Parents". In: International journal of environmental research and public health 17.20, p. 7669.

De Vries, H., Kremers, S., Smeets, T., Brug, J., and Eijmael, K. (2008). "The effectiveness of tailored feedback and action plans in an intervention addressing multiple health behaviors". In: American Journal of Health Promotion 22.6, pp. 417-424.

DeJoy, D. M. (1989). "The optimism bias and traffic accident risk perception". In: Accident Analysis E Prevention 21.4, pp. 333-340.

Dupas, P. (2011). "Do teenagers respond to HIV risk information? Evidence from a field experiment in Kenya". In: American Economic Journal: Applied Economics 3.1, pp. 1-34.

Dupas, P., Huillery, E., and Seban, J. (2018). "Risk information, risk salience, and adolescent sexual behavior: Experimental evidence from Cameroon". In: Journal of Economic Behavior $\&$ Organization 145, pp. 151-175.

Ebner, P., Le Moullec, Y., and Weill, A. (2005). Pollution par les particules atmosphériques: état des connaissances et perspectives de recherche. La Documentation française.

Ferraro, P. J., Miranda, J. J., and Price, M. K. (2011). "The persistence of treatment effects with norm-based policy instruments: evidence from a randomized environmental policy experiment". In: American Economic Review 101.3, pp. 318-22.

Ferraro, P. J. and Price, M. K. (2013). "Using nonpecuniary strategies to influence behavior: evidence from a large-scale field experiment". In: Review of Economics and Statistics 95.1, pp. 64-73.

Fontaine, K. R. (1994). "Effect of dispositional optimism on comparative risk perceptions for developing AIDS". In: Psychological Reports 74.3, pp. 843-846.

Fontaine, K. R. and Smith, S. (1995). "Optimistic bias in cancer risk perception: A cross-national study". In: Psychological reports 77.1, pp. 143-146.

Frasca, D., Marcoccia, M., Tofful, L., Simonetti, G., Perrino, C., and Canepari, S. (2018). "Influence of advanced wood-fired appliances for residential heating on indoor air quality". In: Chemosphere 211, pp. 62-71.

Gee, I. L., Semple, S., Watson, A., and Crossfield, A. (2013). "Nearly $85 \%$ of tobacco smoke is invisible - a confirmation of previous claims". In: Tobacco Control 22.6, pp. 429-429.

Gifford, R., Kormos, C., and McIntyre, A. (2011). "Behavioral dimensions of climate change: drivers, responses, barriers, and interventions". In: Wiley Interdisciplinary Reviews: Climate Change 2.6, pp. 801-827.

Gneezy, U. and List, J. A. (2006). "Putting behavioral economics to work: Testing for gift exchange in labor markets using field experiments". In: Econometrica 74.5, pp. 1365-1384.

Goldstein, N. J., Cialdini, R. B., and Griskevicius, V. (2008). "A room with a viewpoint: Using social norms to motivate environmental conservation in hotels". In: Journal of consumer Research 35.3, pp. $472-482$. 
Gordon, S. B., Bruce, N. G., Grigg, J., Hibberd, P. L., Kurmi, O. P., Lam, K.-b. H., Mortimer, K., Asante, K. P., Balakrishnan, K., Balmes, J., et al. (2014). "Respiratory risks from household air pollution in low and middle income countries". In: The Lancet Respiratory Medicine 2.10, pp. 823-860.

Grange, D., Sommen, C., and Host, S. (2012). "Les perceptions de la pollution de l'air intérieur en Île-de-France". In: Rapport ORS Île-de-France, janv.

Gras, J., Meyer, C., Weeks, I., Gillet, R., Galbally, I., Todd, J., Carnovale, F., Joynt, R., Hinwood, A., Berko, H., et al. (2002). "Technical Report No. 5: Emissions from Domestic Solid Fuel Burning Appliances (Wood-Heaters, Open Fireplaces)". In:

Heydon, J. and Chakraborty, R. (2020). "Can portable air quality monitors protect children from air pollution on the school run? An exploratory study". In: Environmental monitoring and assessment 192.3, pp. 1-16.

Hine, D., Bhullar, N., Marks, A., Kelly, P., and Scott, J. (2011). "Comparing the effectiveness of education and technology in reducing wood smoke pollution: A field experiment". In: Journal of environmental psychology 31.4, pp. 282-288.

Hine, D., Marks, A., Nachreiner, M., Gifford, R., and Heath, Y. (2007). "Keeping the home fires burning: The affect heuristic and wood smoke pollution". In: Journal of Environmental Psychology 27.1, pp. 26-32.

Hoek, G., Kos, G., Harrison, R., Hartog, J. de, Meliefste, K., Brink, H. ten, Katsouyanni, K., Karakatsani, A., Lianou, M., Kotronarou, A., et al. (2008). "Indoor-outdoor relationships of particle number and mass in four European cities". In: Atmospheric Environment 42.1, pp. 156169.

Hofflinger, A., Boso, A., and Oltra, C. (2019). "The home halo effect: How air quality perception is influenced by place attachment". In: Human Ecology 47.4, pp. 589-600.

Hovell, M. F., Bellettiere, J., Liles, S., Nguyen, B., Berardi, V., Johnson, C., Matt, G. E., Malone, J., Boman-Davis, M. C., Quintana, P. J., et al. (2020). "Randomised controlled trial of real-time feedback and brief coaching to reduce indoor smoking". In: Tobacco control 29.2, pp. 183-190.

Hughes, S. C., Bellettiere, J., Nguyen, B., Liles, S., Klepeis, N. E., Quintana, P. J., Berardi, V., Obayashi, S., Bradley, S., Hofstetter, C. R., et al. (2018). "Randomized trial to reduce air particle levels in homes of smokers and children". In: American journal of preventive medicine 54.3, pp. 359-367.

Iribagiza, C., Sharpe, T., Wilson, D., and Thomas, E. A. (2020). "User-centered design of an air quality feedback technology to promote adoption of clean cookstoves". In: Journal of Exposure Science \& Environmental Epidemiology 30.6, pp. 925-936.

Jalan, J. and Somanathan, E. (2008). "The importance of being informed: Experimental evidence on demand for environmental quality". In: Journal of development Economics 87.1, pp. 14-28.

Jensen, R. (2010). "The (perceived) returns to education and the demand for schooling". In: The Quarterly Journal of Economics 125.2, pp. 515-548.

Jiang, Y., Li, K., Tian, L., Piedrahita, R., Yun, X., Mansata, O., Lv, Q., Dick, R. P., Hannigan, M., and Shang, L. (2011). "MAQS: a personalized mobile sensing system for indoor air quality monitoring". In: Proceedings of the 13th international conference on Ubiquitous computing, pp. 271-280.

Karlin, B., Zinger, J. F., and Ford, R. (2015). "The effects of feedback on energy conservation: A meta-analysis." In: Psychological bulletin 141.6, p. 1205.

Kennedy, T., Regehr, G., Rosenfield, J., Roberts, S. W., and Lingard, L. (2004). "Exploring the gap between knowledge and behavior: a qualitative study of clinician action following an educational intervention". In: Academic Medicine 79.5, pp. 386-393.

Klepeis, N., Hughes, S., Edwards, R., Allen, T., Johnson, M., Chowdhury, Z., Smith, K., Boman-Davis, M., Bellettiere, J., and Hovell, M. (2013). "Promoting smoke-free homes: a novel 
behavioral intervention using real-time audio-visual feedback on airborne particle levels". In: PloS one 8.8, e73251.

Klepeis, N., Nelson, W., Ott, W., Robinson, J., Tsang, A., Switzer, P., Behar, J., Hern, S., and Engelmann, W. (2001). "The National Human Activity Pattern Survey (NHAPS): a resource for assessing exposure to environmental pollutants". In: Journal of Exposure Science \&6 Environmental Epidemiology 11.3, pp. 231-252.

Kollmuss, A. and Agyeman, J. (2002). "Mind the gap: why do people act environmentally and what are the barriers to pro-environmental behavior?" In: Environmental education research 8.3, pp. 239-260.

Landrigan, P. J., Fuller, R., Acosta, N. J., Adeyi, O., Arnold, R., Baldé, A. B., Bertollini, R., Bose-O'Reilly, S., Boufford, J. I., Breysse, P. N., et al. (2018). "The Lancet Commission on pollution and health". In: The lancet 391.10119, pp. 462-512.

Langer, S., Ramalho, O., Le Ponner, E., Derbez, M., Kirchner, S., and Mandin, C. (2017). "Perceived indoor air quality and its relationship to air pollutants in French dwellings". In: Indoor air 27.6, pp. 1168-1176.

Lelieveld, J., Pozzer, A., Pöschl, U., Fnais, M., Haines, A., and Münzel, T. (2020). "Loss of life expectancy from air pollution compared to other risk factors: a worldwide perspective". In: Cardiovascular Research.

Loewenstein, G. (1996). "Out of control: Visceral influences on behavior". In: Organizational behavior and human decision processes 65.3, pp. 272-292.

Long, C. M., Suh, H. H., and Koutrakis, P. (2000). "Characterization of indoor particle sources using continuous mass and size monitors". In: Journal of the Air $\&$ Waste Management Association 50.7, pp. $1236-1250$.

Madajewicz, M., Pfaff, A., Van Geen, A., Graziano, J., Hussein, I., Momotaj, H., Sylvi, R., and Ahsan, H. (2007). "Can information alone change behavior? Response to arsenic contamination of groundwater in Bangladesh". In: Journal of development Economics 84.2, pp. 731-754.

Menard, C., Girard, D., Léon, C., Beck, F., and Lamoureux, P. (2008). "Baromètre santé environnement 2007". In: Institut National pour la Promotion et L'éducation à la Santé: Saint-Denis, France.

Molnar, P., Gustafson, P., Johannesson, S., Boman, J., Barregård, L., and Sällsten, G. (2005). "Domestic wood burning and PM2. 5 trace elements: Personal exposures, indoor and outdoor levels". In: Atmospheric Environment 39.14, pp. 2643-2653.

Myers, T. A., Nisbet, M. C., Maibach, E. W., and Leiserowitz, A. A. (2012). "A public health frame arouses hopeful emotions about climate change". In: Climatic change 113.3-4, pp. 1105-1112.

Nasir, Z. A. and Colbeck, I. (2013). "Particulate pollution in different housing types in a UK suburban location". In: Science of The Total Environment 445, pp. 165-176.

Nicolas, M., Quivet, E., Karr G Real, E., Buiron, D., and Maupetit, F. (Sept. 2017). Exposition aux polluants émis par les bougies et les encens dans les environnements intérieurs. Tech. rep. Agence de la transition ecologique.

Oar, Oriá, and Ied (2014). The Inside Story: A Guide to Indoor Air Quality. en. URL: /paper / The - Inside - Story \% 3A - A - Guide - to - Indoor - Air - Quality - Oar - Ori \% C3\%A1 / 611e5fe9c53792df8731072d6e9348834ab419b6 (visited on 02/02/2021).

Oudin, A., Segersson, D., Adolfsson, R., and Forsberg, B. (2018). "Association between air pollution from residential wood burning and dementia incidence in a longitudinal study in Northern Sweden". In: PLoS One 13.6, e0198283.

Pascal, M., Corso, M., Chanel, O., Declercq, C., Badaloni, C., Cesaroni, G., Henschel, S., Meister, K., Haluza, D., Martin-Olmedo, P., et al. (2013). "Assessing the public health impacts of urban air pollution in 25 European cities: results of the Aphekom project". In: Science of the Total Environment 449, pp. 390-400. 
Pelletier, L. G. and Sharp, E. (2008). "Persuasive communication and proenvironmental behaviours: how message tailoring and message framing can improve the integration of behaviours through self-determined motivation." In: Canadian Psychology 49.3.

Perloff, L. S. and Fetzer, B. K. (1986). "Self-other judgments and perceived vulnerability to victimization." In: Journal of Personality and social Psychology 50.3, p. 502.

Pryor, W. (1992). "Biological Effects of Cigarette Smoke, Wood Smoke, and the Smoke From Plastics: The Use of Electron Spin Resonance". In: Free radical biology \& medicine 13.6, pp. 659676.

Rimal, R. N. (2000). "Closing the knowledge-behavior gap in health promotion: The mediating role of self-efficacy". In: Health communication 12.3, pp. 219-237.

Schultz, P. W., Nolan, J. M., Cialdini, R. B., Goldstein, N. J., and Griskevicius, V. (2007). "The constructive, destructive, and reconstructive power of social norms". In: Psychological science 18.5, pp. 429-434.

Schwarzer, R. (2008). "Modeling health behavior change: How to predict and modify the adoption and maintenance of health behaviors". In: Applied psychology 57.1, pp. 1-29.

Sharot, T. (2011). "The optimism bias". In: Current biology 21.23, R941-R945.

Stabile, L., Fuoco, F., and Buonanno, G. (2012). "Characteristics of particles and black carbon emitted by combustion of incenses, candles and anti-mosquito products". In: Building and Environment 56, pp. 184-191.

Stok, F. M., Vet, E. de, Ridder, D. T. de, and Wit, J. B. de (2016). "The potential of peer social norms to shape food intake in adolescents and young adults: a systematic review of effects and moderators". In: Health psychology review 10.3, pp. 326-340.

Tiefenbeck, V., Goette, L., Degen, K., Tasic, V., Fleisch, E., Lalive, R., and Staake, T. (2018). "Overcoming salience bias: How real-time feedback fosters resource conservation". In: Management science 64.3, pp. 1458-1476.

Tiefenbeck, V., Wörner, A., Schöb, S., Fleisch, E., and Staake, T. (2019). "Real-time feedback promotes energy conservation in the absence of volunteer selection bias and monetary incentives". In: Nature Energy 4.1, pp. 35-41.

Tirler, W. and Settimo, G. (2015). Incense, sparklers and cigarettes are significant contributors to indoor benzene and particle levels.

Van Raaij, W. F. and Verhallen, T. M. (1983). "A behavioral model of residential energy use". In: Journal of economic psychology 3.1, pp. 39-63.

Wallace, L. and Howard-Reed, C. (2002). "Continuous monitoring of ultrafine, fine, and coarse particles in a residence for 18 months in 1999-2000". In: Journal of the Air ES Waste Management Association 52.7, pp. 828-844.

Wei, Y., Wang, Y., Di, Q., Choirat, C., Wang, Y., Koutrakis, P., Zanobetti, A., Dominici, F., and Schwartz, J. D. (2019). "Short term exposure to fine particulate matter and hospital admission risks and costs in the Medicare population: time stratified, case crossover study". In: bmj 367.

Weinstein, N. D. (1980). "Unrealistic optimism about future life events." In: Journal of personality and social psychology 39.5, p. 806.

Wong-Parodi, G., Dias, M. B., and Taylor, M. (2018). "Effect of using an indoor air quality sensor on perceptions of and behaviors toward air pollution (Pittsburgh Empowerment Library Study): online survey and interviews". In: JMIR mHealth and uHealth 6.3, e48.

Wu, X., Nethery, R. C., Sabath, M., Braun, D., and Dominici, F. (2020). "Air pollution and COVID-19 mortality in the United States: Strengths and limitations of an ecological regression analysis". In: Science Advances 6.45, eabd4049. 


\section{Tables}

Table 1: Summary statistics and balance check of household characteristics between the three treatment groups

\begin{tabular}{|c|c|c|c|c|c|c|c|}
\hline & $\begin{array}{c}\text { All } \\
\mathrm{N}=281\end{array}$ & $\begin{array}{l}\text { Control } \\
\mathrm{N}=94\end{array}$ & $\begin{array}{l}\text { Information } \\
\qquad \mathrm{N}=93\end{array}$ & $\begin{array}{c}\text { Information }+ \text { PEP } \\
\qquad \mathrm{N}=94\end{array}$ & $\mathrm{C}=\mathrm{I}$ & $\mathrm{C}=\mathrm{I}+\mathrm{PEP}$ & $\mathrm{I}=\mathrm{I}+\mathrm{PEP}$ \\
\hline \multicolumn{8}{|l|}{ Panel A: } \\
\hline \multicolumn{8}{|l|}{ Sociodemographic } \\
\hline Age & $48.94(11.7)$ & $47.9(11.5)$ & $48.1(11.4)$ & $51.0(12.1)$ & 0.889 & 0.072 & 0.096. \\
\hline Household size & $3.25(1.32)$ & $3.4(1.4)$ & $3.3(1.2)$ & $3.2(1.3)$ & 0.596 & 0.325 & 0.625 \\
\hline \multicolumn{8}{|l|}{ Education level: } \\
\hline Baccalaureate or less & $0.1(0.34)$ & $0.2(0.4)$ & $0.1(0.3)$ & $0.1(0.3)$ & 0.141 & 0.527 & 0.395 \\
\hline $\mathrm{BAC}+2$ to +4 & $0.39(0.49)$ & $0.3(0.5)$ & $0.4(0.5)$ & $0.4(0.5)$ & 0.210 & 0.322 & 0.787 \\
\hline $\mathrm{BAC}+5$ or more & $0.46(0.5)$ & $0.5(0.5)$ & $0.5(0.5)$ & $0.5(0.5)$ & 0.947 & 0.947 & 0.894 \\
\hline \multicolumn{8}{|l|}{ Monthly income (€): } \\
\hline Less than 3400 & $0.2(0.4)$ & $0.2(0.4)$ & $0.2(0.4)$ & $0.2(0.4)$ & 0.590 & 0.401 & 0.169 \\
\hline 3400 to 5000 & $0.4(0.48)$ & $0.4(0.5)$ & $0.3(0.5)$ & $0.4(0.5)$ & 0.485 & 0.954 & 0.521 \\
\hline More than 5000 & $0.3(0.47)$ & $0.3(0.5)$ & $0.4(0.5)$ & $0.3(0.5)$ & 0.259 & 0.963 & 0.239 \\
\hline \multicolumn{8}{|l|}{ Panel B: } \\
\hline Household with resp. problems & $0.27(0.44)$ & $0.34(0.48)$ & $0.22(0.41)$ & $0.26(0.44)$ & 0.056 & 0.204 & 0.519 \\
\hline \multicolumn{8}{|l|}{ Subjective health status: } \\
\hline Bad & $0.04(0.2)$ & $0.04(0.20)$ & $0.05(0.23)$ & $0.03(0.18)$ & 0.722 & 0.702 & 0.464 \\
\hline Acceptable & $0.27(0.45)$ & $0.34(0.48)$ & $0.26(0.44)$ & $0.22(0.42)$ & 0.221 & 0.075 & 0.582 \\
\hline Good & $0.59(0.49)$ & $0.52(0.50)$ & $0.55(0.50)$ & $0.68(0.47)$ & 0.712 & 0.025 & 0.063 \\
\hline Excellent & $0.1(0.3)$ & $0.10(0.30)$ & $0.14(0.35)$ & $0.06(0.25)$ & 0.353 & 0.422 & 0.087 \\
\hline Investment in health & $68.32(15.92)$ & $69.70(16.12)$ & $66.91(17.18)$ & $68.11(14.62)$ & 0.254 & 0.478 & 0.610 \\
\hline Ranking of health in priorities & $3.38(1.38)$ & $3.20(1.31)$ & $3.49(1.31)$ & $3.45(1.53)$ & 0.125 & 0.235 & 0.817 \\
\hline \multicolumn{8}{|l|}{ Panel C: } \\
\hline \multicolumn{8}{|l|}{ Environmentalism } \\
\hline Environmental Attitude & $3.68(0.7)$ & $3.57(0.77)$ & $3.82(0.63)$ & $3.66(0.66)$ & 0.016 & 0.395 & 0.087 \\
\hline Environmental Behaviour & $0.59(0.24)$ & $0.57(0.24)$ & $0.60(0.26)$ & $0.60(0.21)$ & 0.451 & 0.403 & 1.000 \\
\hline
\end{tabular}

Panel D:

Pollution perception

Pollution health risk perception $\quad 68(21) \quad 60.39(20.47) \quad 67.80(19.69) \quad 64.86(22.27) \quad 0.411 \quad 0.102 \quad 0.376$

Wood burning listed as:

An outdoor pollution source

An indoor pollution source

$\begin{array}{lll}0.55(0.5) & 0.54(0.50) & 0.49(0.50)\end{array}$

$0.36(0.5) \quad 0.37(0.49) \quad 0.32(0.47)$

$0.54(0.50)$

$0.38(0.49)$

0.539

0.953

0.582

Air quality (1-5 score)

...at home
...in the neighborhood

$3.8(1.1) \quad 3.84(1.12) \quad 3.68(1.09)$

$3.85(1.06)$

$3.73(1.27)$

$3.46(1.28)$

$3.67(1.25)$

0.343

0.969

0.315

3.6(1.3) 
Table 1 - continued from previous page

\begin{tabular}{lcccc} 
& $\begin{array}{c}\text { All } \\
\mathrm{N}=281\end{array}$ & $\begin{array}{c}\text { Control } \\
\mathrm{N}=94\end{array}$ & $\begin{array}{c}\text { Information } \\
\mathrm{N}=93\end{array}$ & $\begin{array}{c}\text { Information }+\mathrm{PEP} \\
\mathrm{N}=94\end{array}$ \\
\hline \hline ...in Île-de-France & $2.44(1.2)$ & $2.73(1.32)$ & $2.36(1.14)$ & $2.27(1.16)$ \\
$\mathrm{C}=\mathrm{I}+\mathrm{PEP}=\mathrm{I}+\mathrm{PEP}$ & 0.052 & 0.019 & 0.648
\end{tabular}

Panel E:

Wood burning practices

\section{Frequency of wood burning:}

More than once a week

$\begin{array}{lllllll}0.52(0.5) & 0.49(0.50) & 0.57(0.50) & 0.48(0.50) & 0.303 & 0.885 & 0.240 \\ 0.32(0.47) & 0.34(0.48) & 0.29(0.46) & 0.33(0.47) & 0.494 & 0.878 & 0.595 \\ 0.17(0.37) & 0.17(0.38) & 0.14(0.35) & 0.19(0.40) & 0.589 & 0.707 & 0.361\end{array}$

$0.17(0.37)$

$0.17(0.38)$

$0.14(0.35)$

$0.19(0.40)$

0.361

Type of equipment:

\begin{tabular}{|c|c|c|c|c|c|c|c|}
\hline Open fireplace & $0.22(0.42)$ & $0.18(0.39)$ & $0.32(0.47)$ & $0.19(0.39)$ & 0.034 & 0.944 & 0.041 \\
\hline \multicolumn{8}{|l|}{ Panel F: } \\
\hline \multicolumn{8}{|c|}{ Indoor Pollution } \\
\hline Baseline PM2.5 & $4.96(7.89)$ & $5.41(11.01)$ & $4.67(5.58)$ & $4.82(5.99)$ & 0.520 & 0.607 & 0.893 \\
\hline
\end{tabular}

Notes: Data from baseline survey. p-values of pairwise t-tests. Mean values are shown and Standard deviation in parentheses. PEP = Personalised Emission Profile 

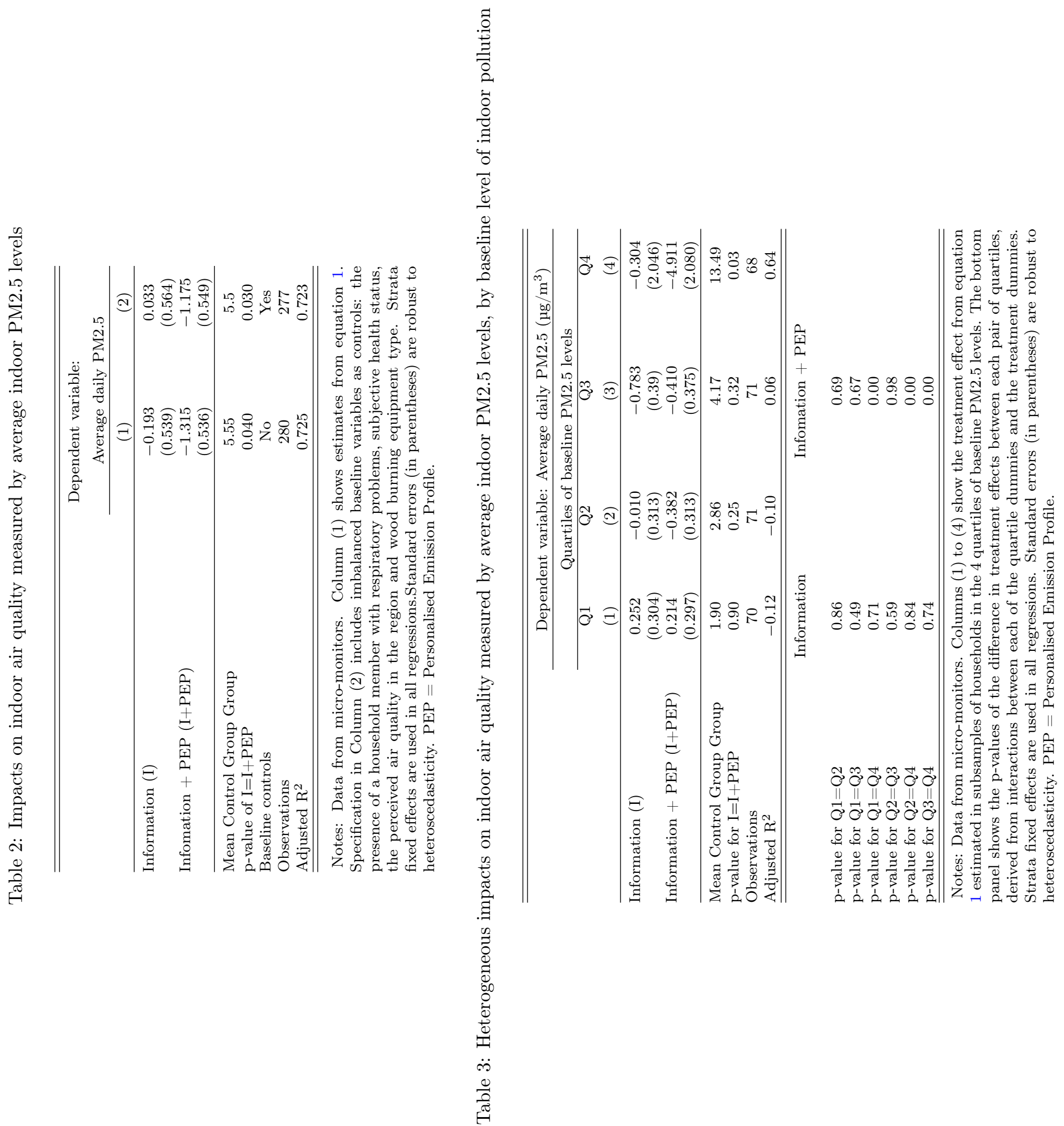


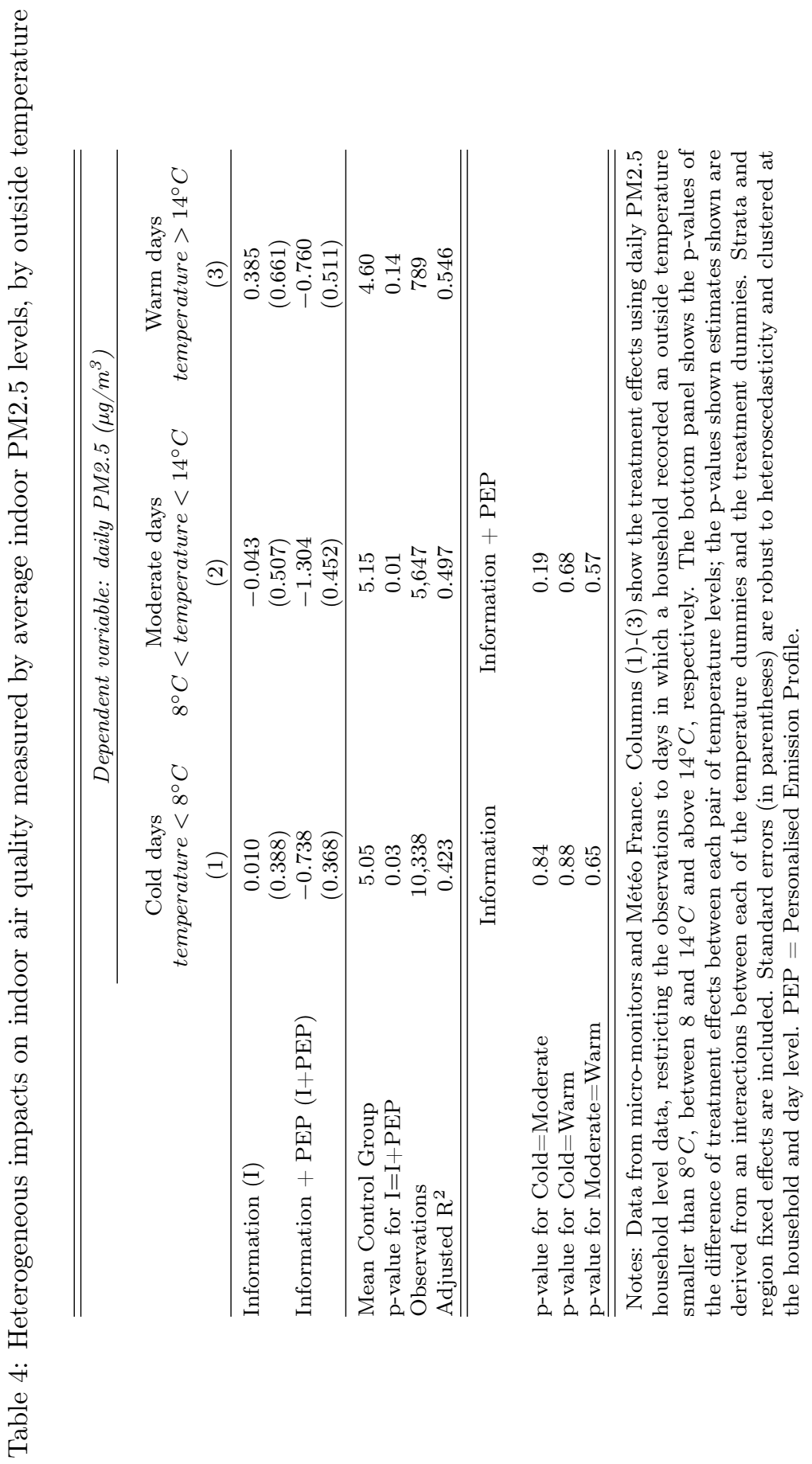




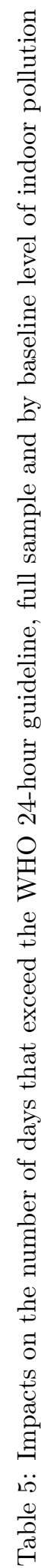

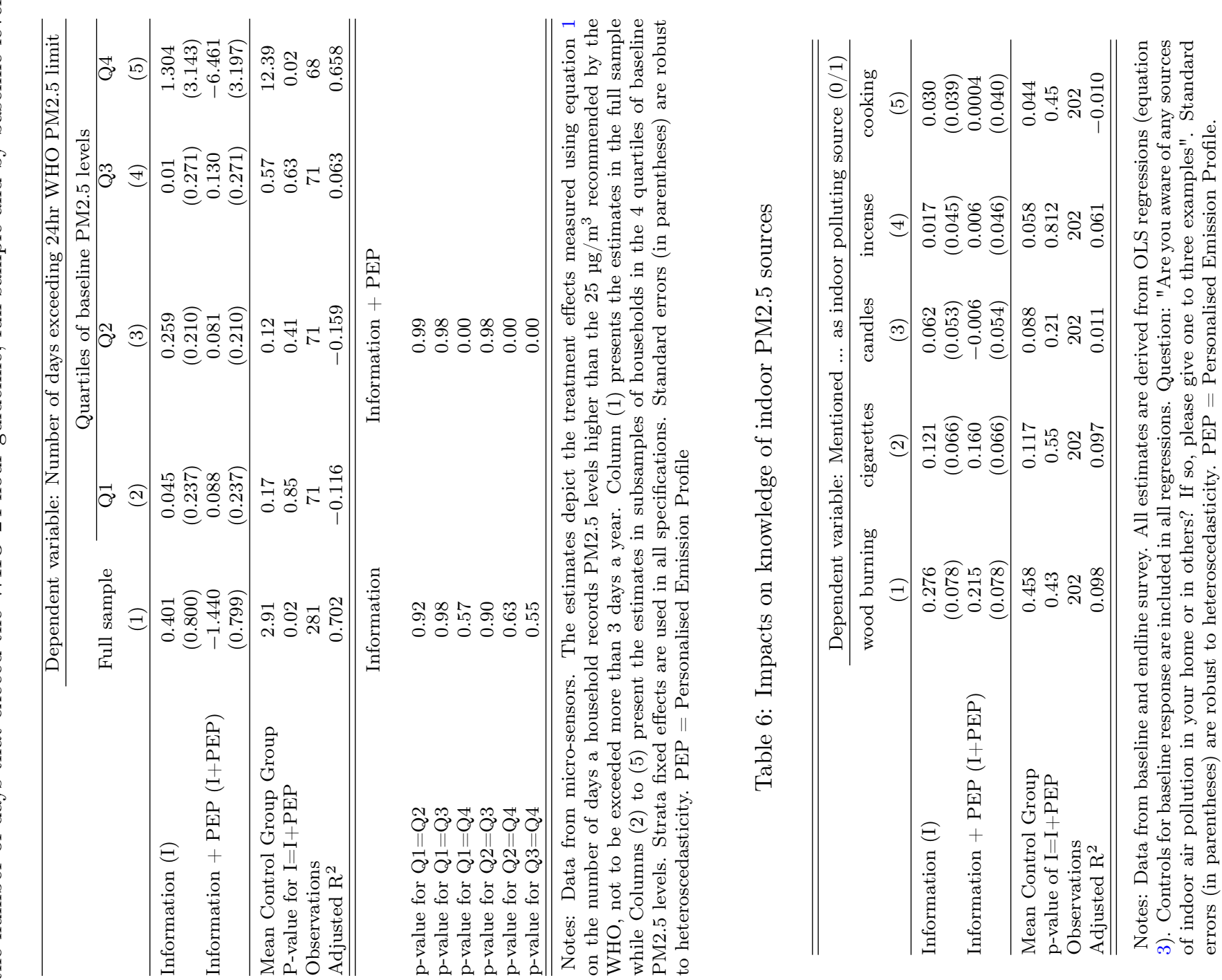




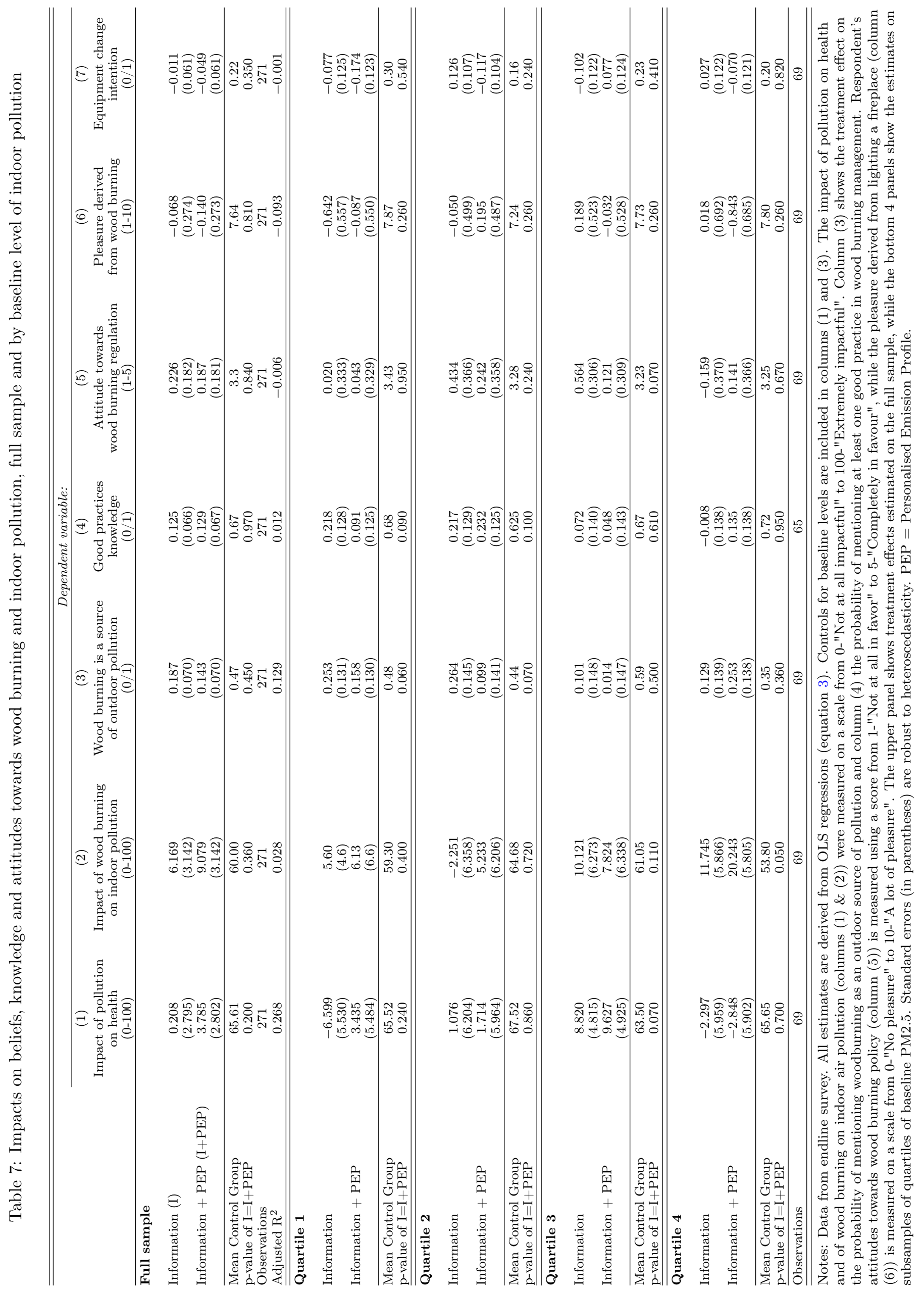




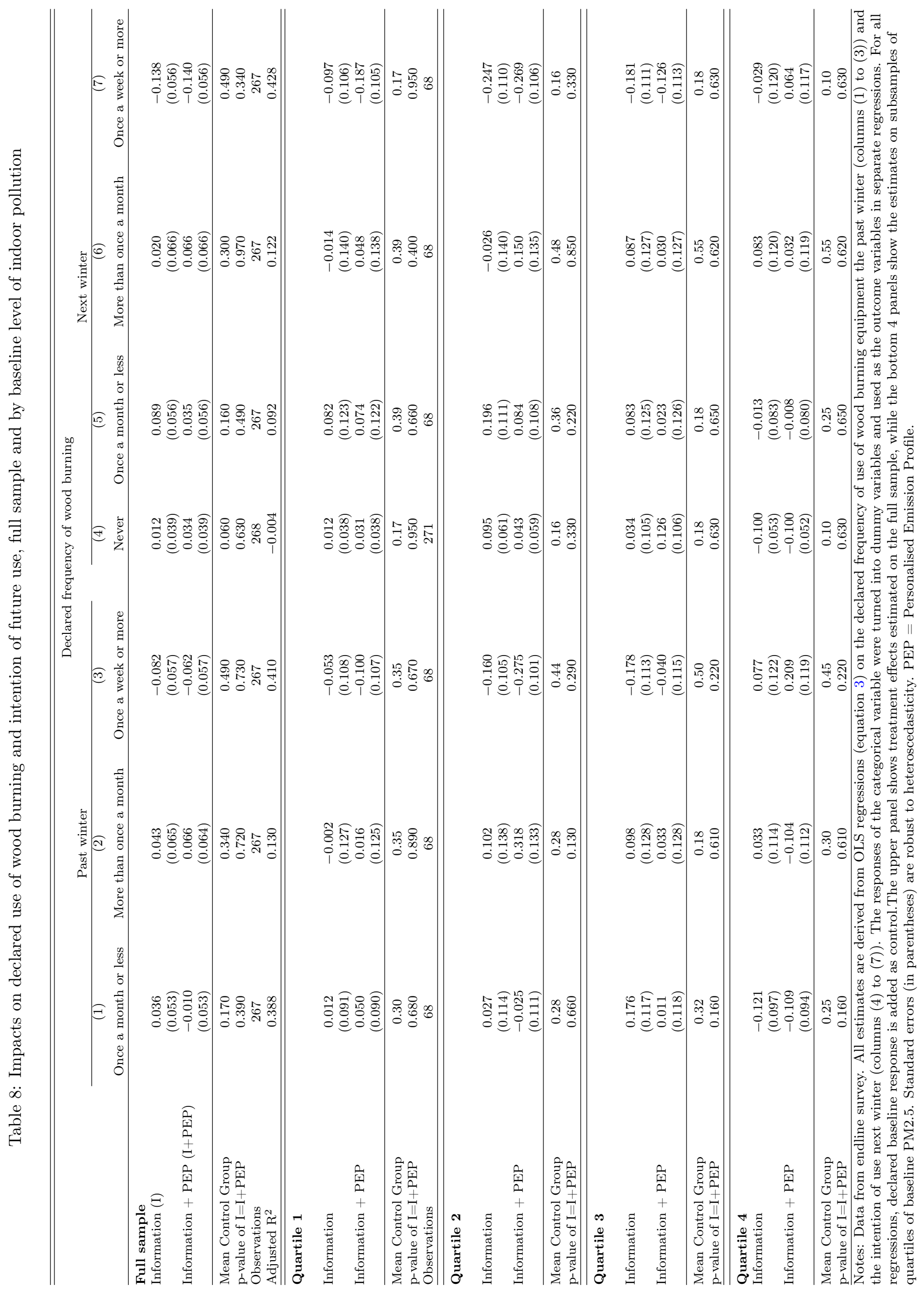




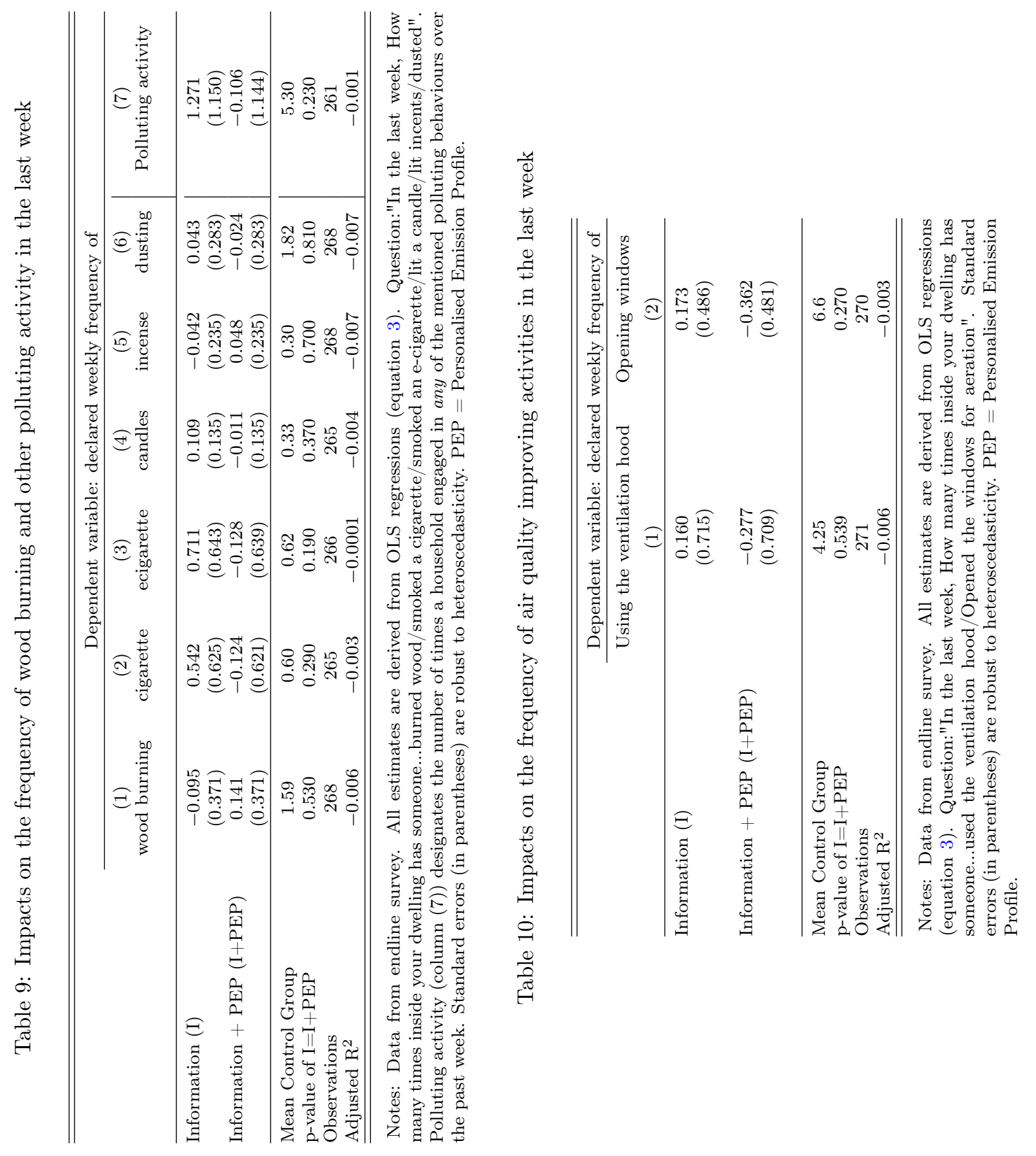




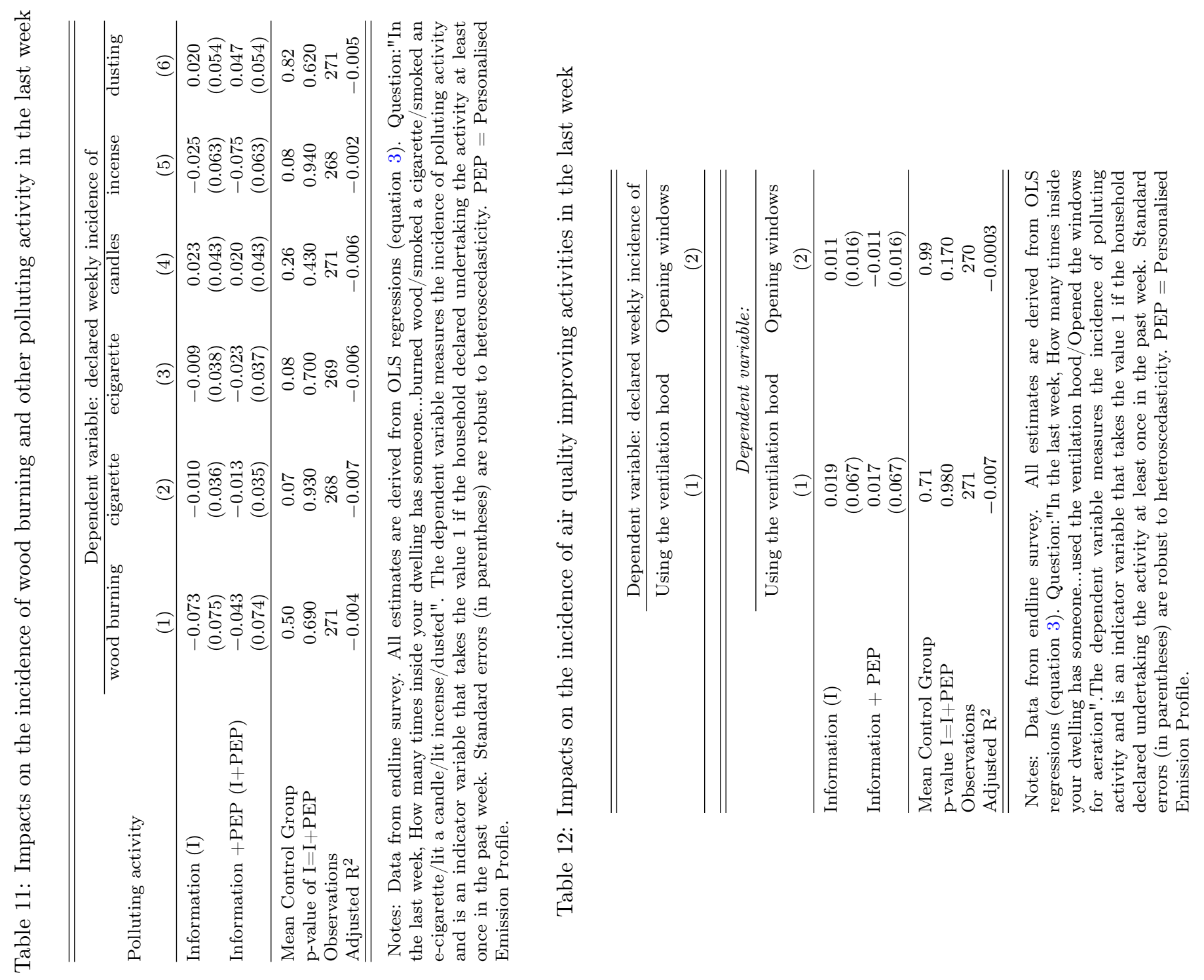




\section{Appendix}

\section{Appendix}

Figure A1: Example of a weekly informational leaflet (Information treatment )

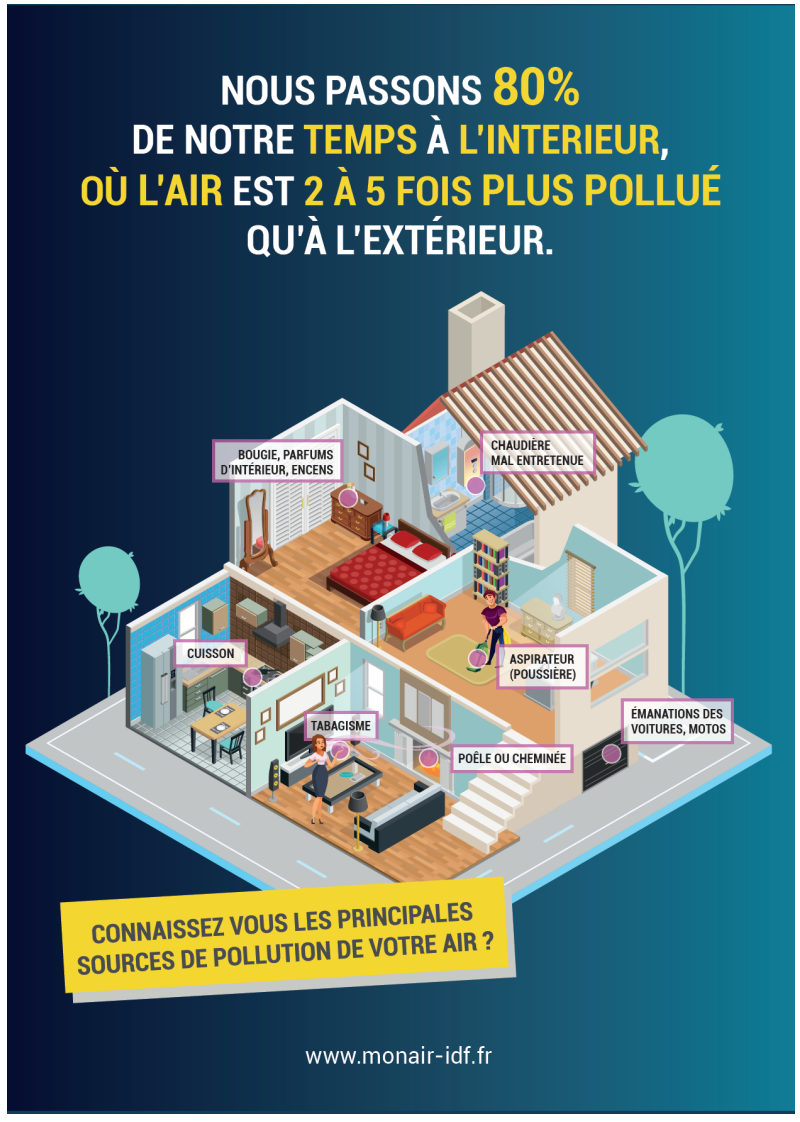

(a) Weekly cover of informational leaflet

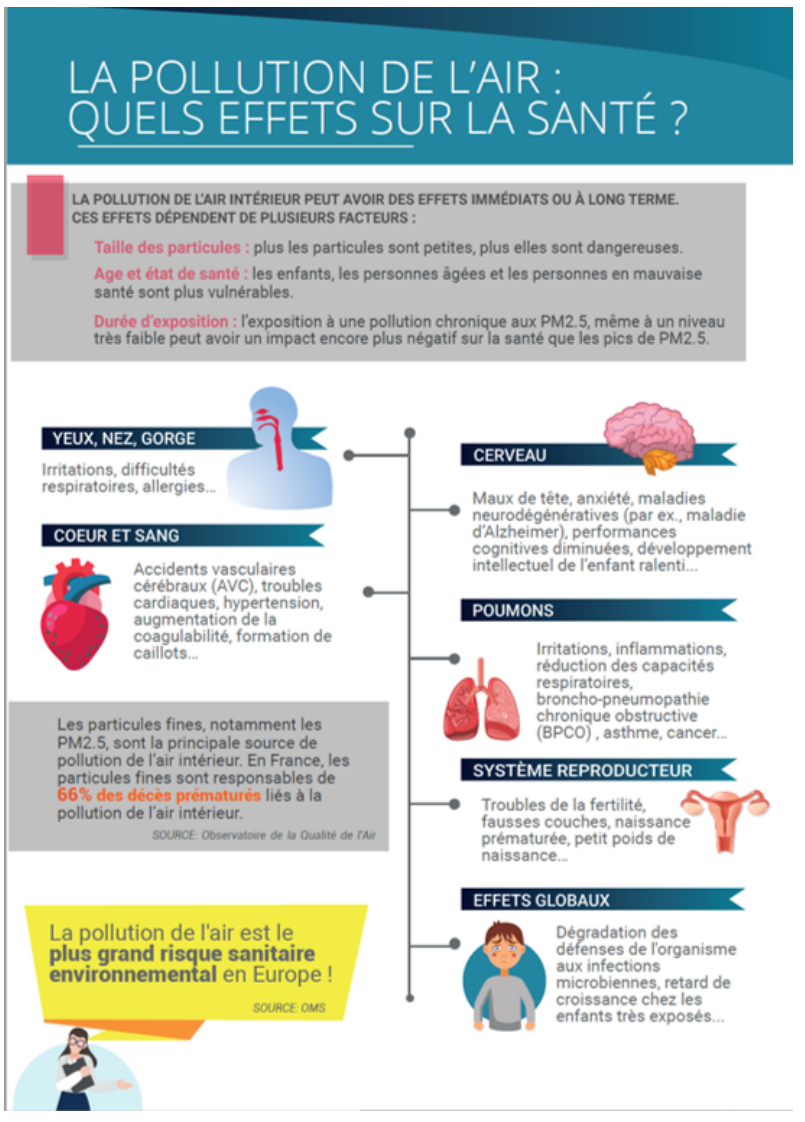

(b) Weekly info-graphics 
Figure A2: Example of a weekly Personalised Emission Profile

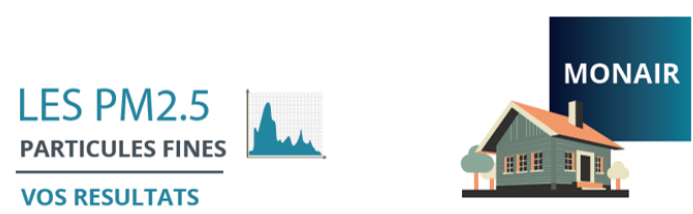

"Les PM2.5 sont nocives, quel que soit le niveau d'exposition", Dr Raaschou-Nielsen, chercheur à la société danoise du cancer. Même en faible quantité, les particules fines sont nocives la recherche a cherché à determiner des seuils en-cessous desquels le risque serait négligeable. Elle n'en a pas trouvé à ce jour. C'est pourquoi l'oMS préconise d'œuvrer à limiter au maximum les niveaux de concentration des particules fines.
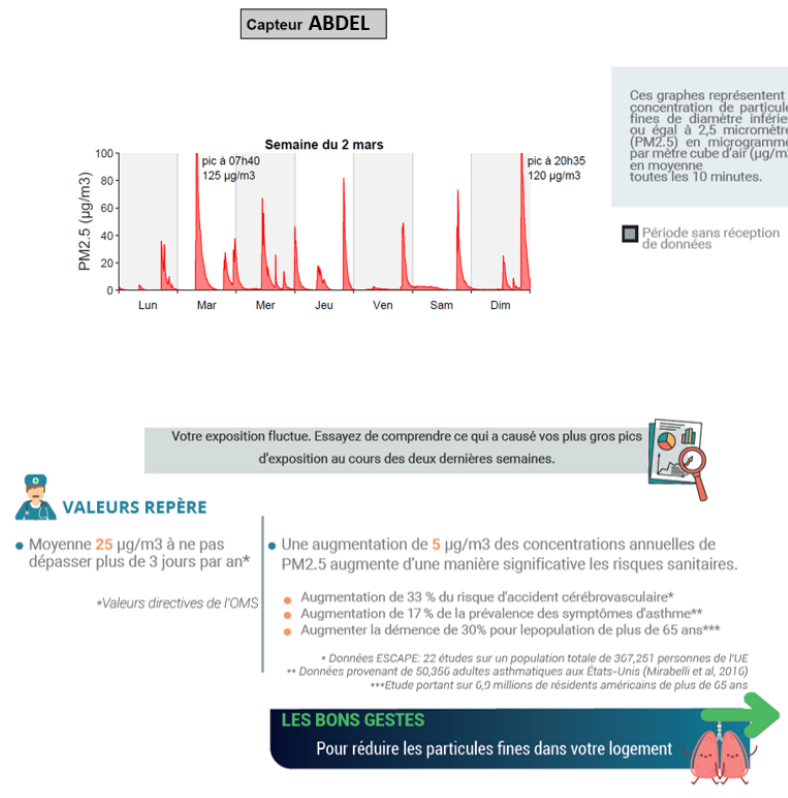

(a) Weekly PM2.5 emission graph

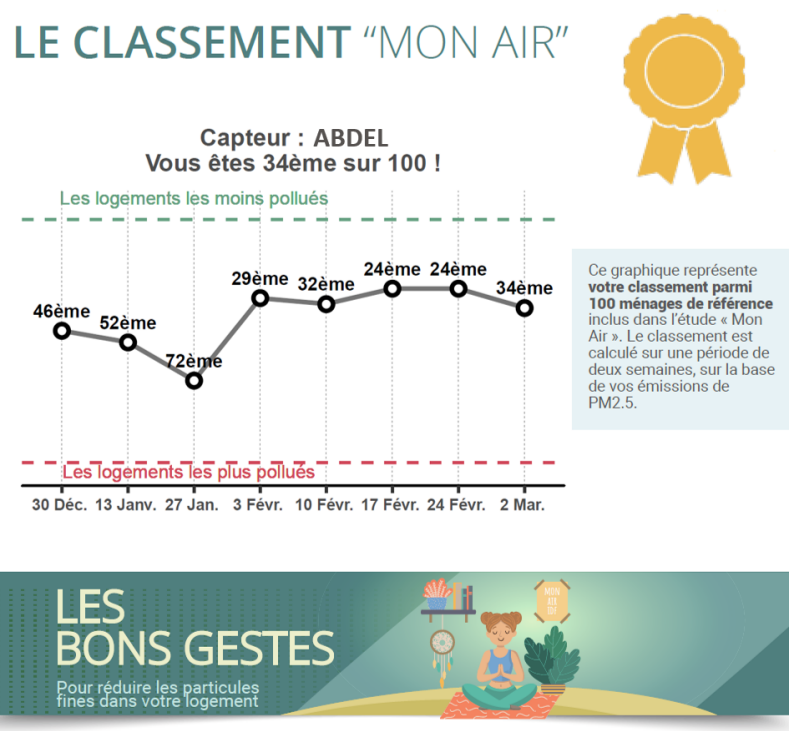

SUR L'AIR INTÉRIEUR, C'EST VOUS QUI AVEZ LA MAIN !

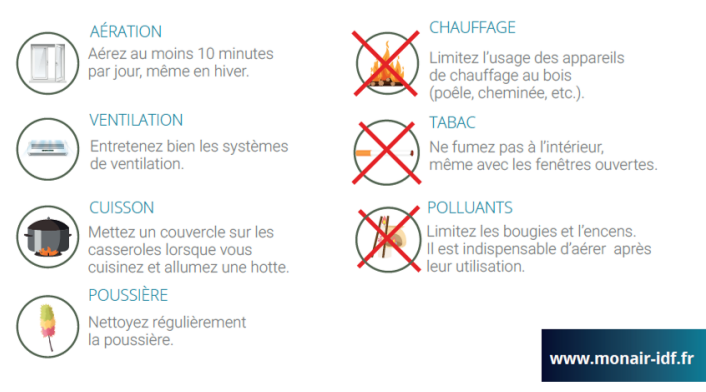

(b) Weekly social comparison graph 
Table A1: Impact of the treatments on the probability of attrition

\begin{tabular}{lc}
\hline \hline & \begin{tabular}{c} 
Dependent variable: \\
\cline { 2 - 2 }
\end{tabular} \\
\hline Missing endline variables \\
$(0 / 1)$
\end{tabular}

Notes : The dependent variable "Missing endline variables" measures the incidence of attrition; it takes the value 0 if the household answered the endline questionnaire and 1 if we received no answer. Coefficients estimated using OLS regression. Standard errors (in parentheses) are robust to heteroscedasticity. PEP $=$ Personalised Emission Profile.

Table A2: Summary descriptives table by quartiles of baseline PM2.5 levels

\begin{tabular}{|c|c|c|c|}
\hline & $\begin{array}{c}\text { Quartiles } 1-3 \\
N=213\end{array}$ & $\begin{array}{c}\text { Quartile } 4 \\
\mathrm{~N}=68\end{array}$ & $\mathrm{p}$-value of $\mathrm{Q} 1-3=\mathrm{Q} 4$ \\
\hline Age & $49.20(11.82)$ & $48.61(11.70)$ & 0.717 \\
\hline Household size & $3.26(1.33)$ & $3.28(1.24)$ & 0.941 \\
\hline \multicolumn{4}{|l|}{ Level of education } \\
\hline Baccalaureate or less & $0.13(0.34)$ & $0.13(0.34)$ & 0.946 \\
\hline $\mathrm{BAC}+2$ to +4 & $0.39(0.49)$ & $0.39(0.49)$ & 0.997 \\
\hline $\mathrm{BAC}+5$ or more & $0.47(0.50)$ & $0.46(0.50)$ & 0.982 \\
\hline \multicolumn{4}{|l|}{ Income level } \\
\hline Less than 3400 & $0.16(0.37)$ & $0.26(0.44)$ & 0.086 \\
\hline 3400 to 5000 & $0.40(0.49)$ & $0.35(0.48)$ & 0.475 \\
\hline More than 5000 & $0.35(0.48)$ & $0.26(0.44)$ & 0.153 \\
\hline \multicolumn{4}{|l|}{ Polluting activity } \\
\hline Presence of smoker in the household & $0.061(0.23)$ & $0.29(0.45)$ & 0.00 \\
\hline Use of incense & $0.13(0.33)$ & $0.11(0.31)$ & 0.65 \\
\hline Presence of a pet & $0.50(0.50)$ & $0.56(0.49)$ & 0.46 \\
\hline \multicolumn{4}{|l|}{ Wood burning frequency } \\
\hline$\overline{\text { Once a week or more }}$ & $0.48(0.50)$ & $0.65(0.48)$ & 0.010 \\
\hline More than once a month & $0.34(0.47)$ & $0.26(0.44)$ & 0.230 \\
\hline Once a month or less & $0.19(0.39)$ & $0.09(0.28)$ & 0.022 \\
\hline \multicolumn{4}{|l|}{ Wood burning equipment type } \\
\hline$\overline{\text { Open fireplace }}$ & $0.22(0.42)$ & $0.23(0.43)$ & 0.878 \\
\hline Pollution health risk perception & $69.03(20.20)$ & $63.30(23.94)$ & 0.078 \\
\hline Investment in health & $67.99(15.73)$ & $67.77(16.66)$ & 0.925 \\
\hline Wood burning listed as outdoor pollution source & $0.56(0.50)$ & $0.49(0.50)$ & 0.308 \\
\hline Household member with respiratory problems & $0.27(0.44)$ & $0.25(0.44)$ & 0.955 \\
\hline Ranking of health in priorities & $3.34(1.42)$ & $3.48(1.26)$ & 0.452 \\
\hline \multicolumn{4}{|l|}{ Subjective health status } \\
\hline$\overline{\mathrm{Bad}}$ & $0.04(0.20)$ & $0.04(0.21)$ & 0.891 \\
\hline Acceptable & $0.24(0.43)$ & $0.38(0.49)$ & 0.037 \\
\hline Good & $0.61(0.49)$ & $0.52(0.50)$ & 0.213 \\
\hline Excellent & $0.11(0.32)$ & $0.06(0.24)$ & 0.124 \\
\hline
\end{tabular}

Notes: Data from baseline survey. p-values estimated using independent samples t-tests. Standard errors (in parentheses) are robust to heteroscedasticity. 
Table A3: Correlation between indoor levels of PM2.5 and self-reported behaviour

\begin{tabular}{cc}
\hline \hline & Dependent variable: \\
\cline { 2 - 2 } & Average daily PM2.5 \\
\hline
\end{tabular}

$\underline{\text { Equipment type }}$

Open fireplace

Ref.

Closed fireplace or insert

$-3.255$

$(1.279)$

$-2.902$

Wood stove

(1.368)

Pellet stove

$-5.820$

(2.426)

Wood burning frequency baseline

Once a week or more

Ref.

More than once a month

$-1.131$

(0.977)

Once a month or less

$-3.701$

Household Income

Less than 3400

Ref.

3400 to 5000

$-3.311$

(1.256)

More than 5000

$-4.051$

(1.324)

Education

Less than $\mathrm{BAC}+2 \quad$ Ref.

$\mathrm{BAC}+2$ to $+4 \quad 0.517$

(1.407)

$\begin{array}{ll}\mathrm{BAC}+5 \text { or more } & 0.235\end{array}$

(1.457)

Declared frequency in past week $(0 / 1)$

\begin{tabular}{lc}
\hline Wood burning & 0.997 \\
Cigarette & $(0.721)$ \\
& 18.142 \\
E-cigarette & $1.572)$ \\
& -2.245 \\
Candles & $(1.580)$ \\
& -0.470 \\
Encens & $(0.903)$ \\
& 0.414 \\
Dusting & $(1.299)$ \\
& 0.869 \\
Ventilation hood & $(1.047)$ \\
& -0.845 \\
Window opening & $(0.792)$ \\
& 0.623 \\
Observations & $(3.377)$ \\
Adjusted ${ }^{2}$ & 281 \\
Residual Std. Error & 0.068 \\
F Statistic & $6.576(\mathrm{df}=260)$ \\
\hline \hline
\end{tabular}

Notes: estimates from OLS regression of average daily PM2.5 regressed on households characteristics. Standard errors (in parentheses) are robust to heteroscedasticity. 